\title{
Biogeography of jellyfish in the North Atlantic, by traditional and genomic methods
}

\author{
P. Licandro ${ }^{1}$, M. Blackett ${ }^{1,2}$, A. Fischer ${ }^{1}$, A. Hosia ${ }^{3,4}$, J. Kennedy ${ }^{5}$, R. R. Kirby ${ }^{6}$, K. Raab ${ }^{7,8}$, R. Stern ${ }^{1}$, \\ and $\mathbf{P}$. Tranter ${ }^{1}$ \\ ${ }^{1}$ Sir Alister Hardy Foundation for Ocean Science (SAHFOS), The Laboratory, Citadel Hill, \\ Plymouth PL1 2PB, UK \\ ${ }^{2}$ School of Ocean and Earth Science, National Oceanography Centre, University of Southampton, \\ European Way, Southampton SO14 3ZH, UK \\ ${ }^{3}$ University Museum of Bergen, Department of Natural History, University of Bergen, P.O. Box 7800, \\ 5020 Bergen, Norway \\ ${ }^{4}$ Institute of Marine Research, P.O. Box 1870, 5817 Nordnes, Bergen, Norway \\ ${ }^{5}$ Department of Environment, Fisheries and Sealing Division, Box 1000 Station 1390, Iqaluit, Nunavut, \\ XOA OHO, Canada \\ ${ }^{6}$ Marine Institute, Plymouth University, Drake Circus, Plymouth PL4 8AA, UK \\ ${ }^{7}$ Institute for Marine Resources and Ecosystem Studies (IMARES), P.O. Box 68, \\ 1970 AB Ijmuiden, the Netherlands \\ ${ }^{8}$ Wageningen University and Research Centre, P.O. Box 9101, 6700 HB Wageningen, the Netherlands
}

Correspondence to: P. Licandro (prli@sahfos.ac.uk)

Received: 26 February 2014 - Published in Earth Syst. Sci. Data Discuss.: 5 November 2014

Revised: 30 April 2015 - Accepted: 14 May 2015 - Published: 15 July 2015

\begin{abstract}
Scientific debate on whether or not the recent increase in reports of jellyfish outbreaks represents a true rise in their abundance has outlined a lack of reliable records of Cnidaria and Ctenophora. Here we describe different jellyfish data sets produced within the EU programme EURO-BASIN. These data were assembled with the aim of creating an improved baseline and providing new data that can be used to evaluate the current diversity and standing stocks of jellyfish in the North Atlantic region.

Using a net adapted to sample gelatinous zooplankton quantitatively, cnidarians and ctenophores were collected from the epipelagic layer during spring-summer 2010-2013, in inshore and offshore waters between lat 59 and $68^{\circ} \mathrm{N}$ and long $62^{\circ} \mathrm{W}$ and $5^{\circ} \mathrm{E}$. Jellyfish were also identified and counted in samples opportunistically collected by other sampling equipment in the same region and at two coastal stations in the Bay of Biscay and in the Gulf of Cádiz. Continuous Plankton Recorder (CPR) samples collected in 2009-2012 were re-analysed with the aim of identifying the time and location of cnidarian blooms across the North Atlantic Basin.

Overall the data show high variability in jellyfish abundance and diversity, mainly in relation to different water masses and bathymetry. Higher densities were generally recorded on the shelves, where the communities tend to be more diverse due to the presence of meropelagic medusae. Comparison of net records from the G.O. Sars transatlantic cruise shows that information on jellyfish diversity differs significantly depending on the sampling gear utilised. Indeed, the big trawls mostly collect relatively large scyphozoan and hydrozoan species, while small hydrozoans and early stages of Ctenophora are only caught by smaller nets.

Based on CPR data from 2009 to 2012, blooms of cnidarians occurred in all seasons across the whole North Atlantic Basin. Molecular analysis revealed that, contrary to previous hypotheses, the CPR is able to detect blooms of meroplanktonic and holoplanktonic hydrozoans and scyphozoans.

Through combination of different types of data, key jellyfish taxa for the spring-summer period were identified in the northern North Atlantic regions. Key species for the central and southern North Atlantic could be inferred
\end{abstract}


based on the blooms identified by the CPR survey, although this should be confirmed further by comparison with quantitative data.

The identification by DNA barcoding of 23 jellyfish specimens collected during the EURO-BASIN cruises contributes to increasing the still very limited number of jellyfish sequences available on GenBank.
All
observations
presented here
can
be
downloaded
from
PANGAEA

(http://doi.pangaea.de/10.1594/PANGAEA.835732).

\section{Introduction}

In recent years a global increase in jellyfish abundance has been widely debated, but a general consensus on this matter has not yet been achieved. While a part of the scientific community has pointed out increasing frequencies of jellyfish outbreak events in marine and estuarine regions worldwide (e.g. Brodeur et al., 1999; Mills, 2001; Xian et al., 2005; Kawahara et al., 2006; Atrill et al., 2007; Licandro et al., 2010; Brotz et al., 2012), some studies have suggested that the rise in jellyfish abundance is just an up-phase of oscillations that characterise their long-term periodicity (Condon et al., 2013). Within this debate, it has been recognised that there is a lack of reliable jellyfish data (Purcell, 2009; Brotz et al., 2012; Condon et al., 2012). "Jellyfish" is here used to describe a defined plankton functional group, i.e. gelatinous carnivores belonging to the two phyla Cnidaria and Ctenophora. The identification of those groups can be extremely challenging, due to their morphological complexity (Cnidaria, for instance, might be planktonic and benthonic, solitary or colonial, with a large range of different shapes and sizes), their fragility (which can compromise some key morphological features) and the poor knowledge of their taxonomy.

Conventional sampling methodologies are often inappropriate to quantify jellyfish standing stocks and to evaluate the diversity of their populations. A large volume of seawater must be filtered to collect planktonic jellyfish, which are usually highly dispersed (Purcell, 2009). Silk or polyester mesh materials are preferable, as nylon or stramine mesh (traditionally used to collect plankton samples) may severely damage or destroy many delicate species of gelatinous zooplankton (Braconnot, 1971). A slow towing speed $\left(0.5-1 \mathrm{~m} \mathrm{~s}^{-1}\right)$ is fundamental for the collection of intact specimens that would be otherwise badly damaged.

Here we describe different jellyfish data sets produced within the EU programme EURO-BASIN, assembled with the aim of presenting an up-to-date overview of the diversity and the abundance of North Atlantic jellyfish. The use of different sampling gears provides the opportunity to discuss the limitation of each methodological approach and its influence on the quality of the data.

\section{Data}

\subsection{Net data}

Jellyfish were collected with different types of nets in several North Atlantic regions (Fig. 1 and Table 1). Sampling was mainly done using a "gentle" net, hereafter called the "jellynet", which was designed following the specifications of a Régent net, which has been shown to be suitable for quantitative collections of gelatinous organisms (Braconnot, 1971). The jellynet has a $1 \mathrm{~m}$ diameter mouth fitted with a $2 \mathrm{~m}$ long tapered net and a large non-filtering rigid cod-end $14 \mathrm{~cm}$ in diameter and $30 \mathrm{~cm}$ in length. The net mesh is knitted polyester with a nominal $800 \mu \mathrm{m}$ mesh aperture. The jellynet was used to collect jellyfish in the epipelagic layer (0$200 \mathrm{~m}$ ) across the whole North Atlantic Basin, during three main EURO-BASIN cruises, i.e. the 2012 Meteor cruise, the 2012 Icelandic cruise and the transatlantic 2013 G.O. Sars cruise (Table 2 and Fig. 1). The same net was used to sample jellyfish off the Cumberland Peninsula (Canada) in 2011 (i.e. Arctic cruise, Table 2 and Fig. 1).

Jellyfish were also identified and counted in samples opportunistically collected with other sampling gears (Table 3 and Fig. 1). During the G.O. Sars cruise they were collected at different depths in the $0-1000 \mathrm{~m}$ layer using a standard $1 \mathrm{~m}^{2}$ Multiple Opening/Closing Net and Environmental Sensing System (MOCNESS; Wiebe and Benfield, 2003) (quantitative data), Harstad (Nedreaas and Smedstad, 1987) and macroplankton trawls (qualitative data) (Tables 1 and 3).

Even though the bongo net is not particularly suitable to quantitatively catch jellyfish specimens, samples collected using this gear during 2010 in the Gulf of Cádiz (i.e. IEO data set, Table 3) and in the Bay of Biscay (i.e. AZTI data set, Table 3) were analysed to provide baseline information on the relative abundance and composition of jellyfish populations in the southern regions of the North Atlantic. The identification of jellyfish was, whenever possible, undertaken immediately after collection, with the exception of samples collected off the Cumberland Peninsula, in the Gulf of Cádiz and in the Bay of Biscay that were analysed up to 1 year after collection. The taxonomic identifications, based on key references on jellyfish taxonomy (Russel, 1953; Kramp, 1959; Kirkpatrick and Pugh, 1984; Carré and Carré, 1993; Wrobel and Mills, 1998; Mianzan and Cornelius, 1999; Pugh, 1999; Haddock et al., 2005; Bouillon et al., 2006; Licandro and 

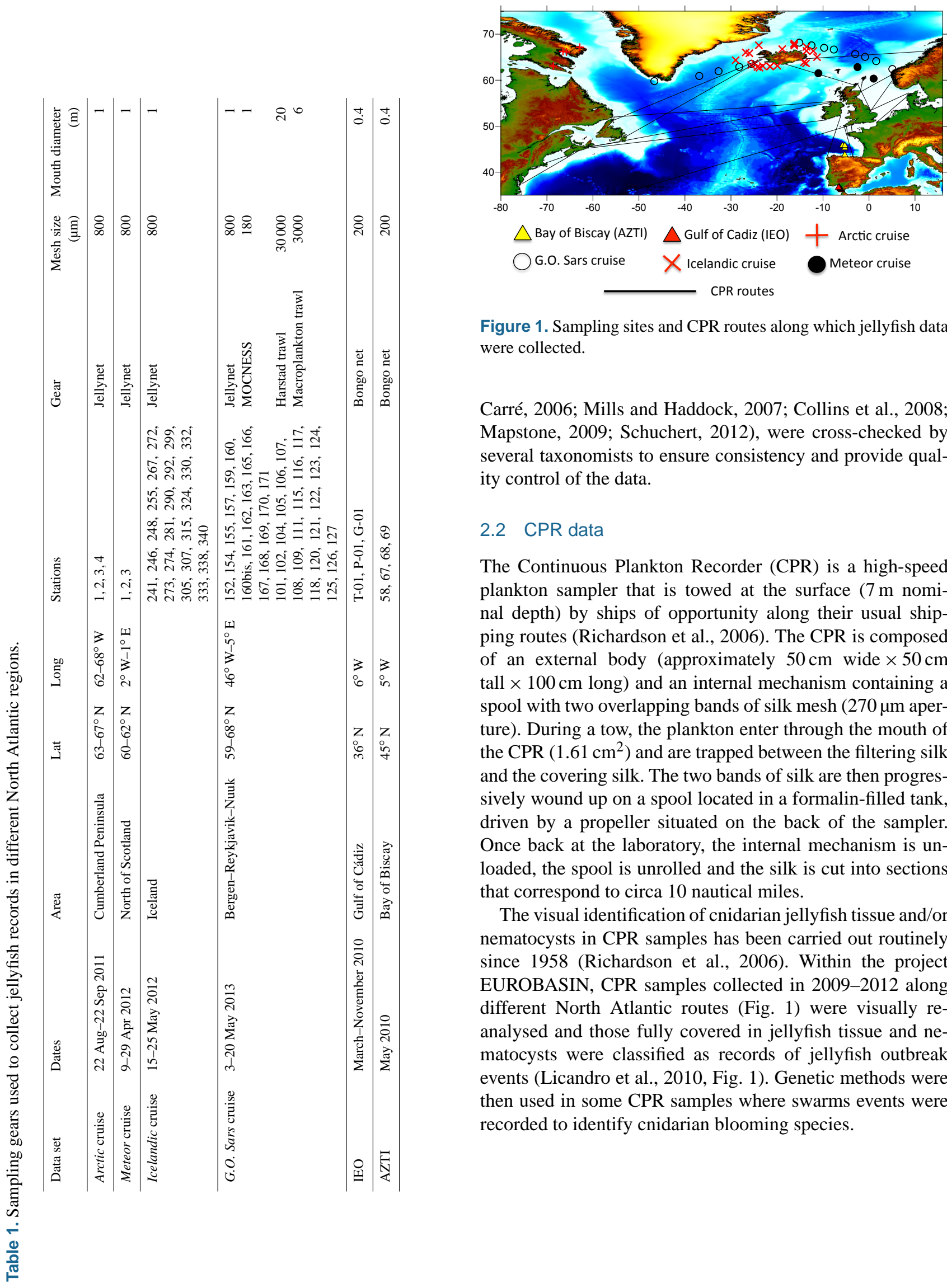

Figure 1. Sampling sites and CPR routes along which jellyfish data were collected.

Carré, 2006; Mills and Haddock, 2007; Collins et al., 2008; Mapstone, 2009; Schuchert, 2012), were cross-checked by several taxonomists to ensure consistency and provide quality control of the data.

\subsection{CPR data}

The Continuous Plankton Recorder (CPR) is a high-speed plankton sampler that is towed at the surface $(7 \mathrm{~m} \mathrm{nomi-}$ nal depth) by ships of opportunity along their usual shipping routes (Richardson et al., 2006). The CPR is composed of an external body (approximately $50 \mathrm{~cm}$ wide $\times 50 \mathrm{~cm}$ tall $\times 100 \mathrm{~cm}$ long) and an internal mechanism containing a spool with two overlapping bands of silk mesh $(270 \mu \mathrm{m}$ aperture). During a tow, the plankton enter through the mouth of the CPR $\left(1.61 \mathrm{~cm}^{2}\right)$ and are trapped between the filtering silk and the covering silk. The two bands of silk are then progressively wound up on a spool located in a formalin-filled tank, driven by a propeller situated on the back of the sampler. Once back at the laboratory, the internal mechanism is unloaded, the spool is unrolled and the silk is cut into sections that correspond to circa 10 nautical miles.

The visual identification of cnidarian jellyfish tissue and/or nematocysts in CPR samples has been carried out routinely since 1958 (Richardson et al., 2006). Within the project EUROBASIN, CPR samples collected in 2009-2012 along different North Atlantic routes (Fig. 1) were visually reanalysed and those fully covered in jellyfish tissue and nematocysts were classified as records of jellyfish outbreak events (Licandro et al., 2010, Fig. 1). Genetic methods were then used in some CPR samples where swarms events were recorded to identify cnidarian blooming species. 
Table 2. List of stations in which jellyfish were collected using the Jellynet. Main sampling information is also indicated. Data from Licandro and Blackett (2014), Licandro and Hosia (2014), Licandro and Kennedy (2014), Licandro and Raab (2014) and Licandro et al. (2014).

\begin{tabular}{|c|c|c|c|c|c|c|}
\hline Station & Latitude & Longitude & $\begin{array}{r}\text { Sampling depth } \\
(\mathrm{m})\end{array}$ & $\begin{array}{r}\text { Time } \\
\text { (start, local) }\end{array}$ & Date & $\begin{array}{r}\text { Bottom depth } \\
\text { (m) }\end{array}$ \\
\hline \multicolumn{7}{|c|}{ Arctic cruise } \\
\hline 1 & $66^{\circ} 08^{\prime} 43^{\prime \prime} \mathrm{N}$ & $65^{\circ} 45^{\prime} 18^{\prime \prime} \mathrm{W}$ & 150 & $17: 44$ & $22 / 08 / 2011$ & 150 \\
\hline 2 & $65^{\circ} 75^{\prime} 95^{\prime \prime} \mathrm{N}$ & $65^{\circ} 91^{\prime} 23^{\prime \prime} \mathrm{W}$ & 200 & $11: 40$ & $25 / 08 / 2011$ & 200 \\
\hline 3 & $67^{\circ} 08^{\prime} 48^{\prime \prime} \mathrm{N}$ & $62^{\circ} 50^{\prime} 82^{\prime \prime} \mathrm{W}$ & 200 & $13: 33$ & $12 / 09 / 2011$ & 334 \\
\hline 4 & $63^{\circ} 04^{\prime} 00^{\prime \prime} \mathrm{N}$ & $68^{\circ} 36^{\prime} 00^{\prime \prime} \mathrm{W}$ & 200 & $15: 45$ & $22 / 09 / 2011$ & 200 \\
\hline \multicolumn{7}{|c|}{ Meteor cruise } \\
\hline 1 & $61^{\circ} 30^{\prime} 00^{\prime \prime} \mathrm{N}$ & $10^{\circ} 59^{\prime} 99^{\prime \prime} \mathrm{W}$ & 200 & $07: 45$ & 09/04/2012 & 1350 \\
\hline 1 & $61^{\circ} 30^{\prime} 00^{\prime \prime} \mathrm{N}$ & $10^{\circ} 59^{\prime} 99^{\prime \prime} \mathrm{W}$ & 200 & $08: 13$ & 09/04/2012 & 1350 \\
\hline 1 & $61^{\circ} 30^{\prime} 00^{\prime \prime} \mathrm{N}$ & $10^{\circ} 59^{\prime} 99^{\prime \prime} \mathrm{W}$ & 200 & $17: 27$ & 09/04/2012 & 1350 \\
\hline 1 & $61^{\circ} 30^{\prime} 00^{\prime \prime} \mathrm{N}$ & $10^{\circ} 59^{\prime} 99^{\prime \prime} \mathrm{W}$ & 200 & $17: 58$ & 09/04/2012 & 1350 \\
\hline 1 & $61^{\circ} 30^{\prime} 01^{\prime \prime} \mathrm{N}$ & $10^{\circ} 59^{\prime} 99^{\prime \prime} \mathrm{W}$ & 200 & $05: 37$ & $10 / 04 / 2012$ & 1350 \\
\hline 1 & $61^{\circ} 29^{\prime} 95^{\prime \prime} \mathrm{N}$ & $11^{\circ} 0^{\prime} 06^{\prime \prime} \mathrm{W}$ & 200 & 06:07 & $10 / 04 / 2012$ & 1350 \\
\hline 1 & $61^{\circ} 29^{\prime} 99^{\prime \prime} \mathrm{N}$ & $11^{\circ} 0^{\prime} 00^{\prime \prime} \mathrm{W}$ & 200 & $18: 04$ & $10 / 04 / 2012$ & 1350 \\
\hline 1 & $61^{\circ} 29^{\prime} 99^{\prime \prime} \mathrm{N}$ & $11^{\circ} 0^{\prime} 01^{\prime \prime} \mathrm{W}$ & 200 & $18: 35$ & $10 / 04 / 2012$ & 1350 \\
\hline 2 & $62^{\circ} 50^{\prime} 00^{\prime \prime \prime} \mathrm{N}$ & $2^{\circ} 30^{\prime} 00^{\prime \prime \prime} \mathrm{W}$ & 200 & $16: 14$ & $12 / 04 / 2012$ & 1300 \\
\hline 2 & $62^{\circ} 49^{\prime \prime} 99^{\prime \prime} \mathrm{N}$ & $2^{\circ} 30^{\prime} 11^{\prime \prime} \mathrm{W}$ & 200 & $16: 41$ & $12 / 04 / 2012$ & 1300 \\
\hline 2 & $62^{\circ} 50^{\prime} 01^{\prime \prime} \mathrm{N}$ & $2^{\circ} 29^{\prime} 98^{\prime \prime} \mathrm{W}$ & 200 & $05: 54$ & $13 / 04 / 2012$ & 1300 \\
\hline 2 & $62^{\circ} 50^{\prime} 01^{\prime \prime} \mathrm{N}$ & $2^{\circ} 29^{\prime} 98^{\prime \prime} \mathrm{W}$ & 200 & $06: 25$ & $13 / 04 / 2012$ & 1300 \\
\hline 2 & $62^{\circ} 50^{\prime} 04^{\prime \prime} \mathrm{N}$ & $2^{\circ} 30^{\prime} 16^{\prime \prime} \mathrm{W}$ & 400 & $11: 29$ & $13 / 04 / 2012$ & 1300 \\
\hline 2 & $62^{\circ} 50^{\prime} 01^{\prime \prime} \mathrm{N}$ & $2^{\circ} 30^{\prime} 11^{\prime \prime} \mathrm{W}$ & 400 & $02: 30$ & $14 / 04 / 2012$ & 1300 \\
\hline 2 & $62^{\circ} 50^{\prime} 01^{\prime \prime} \mathrm{N}$ & $2^{\circ} 30^{\prime} 05^{\prime \prime} \mathrm{W}$ & 200 & $04: 47$ & $14 / 04 / 2012$ & 1300 \\
\hline 2 & $62^{\circ} 50^{\prime} 01^{\prime \prime} \mathrm{N}$ & $2^{\circ} 30^{\prime} 05^{\prime \prime} \mathrm{W}$ & 200 & $05: 17$ & $14 / 04 / 2012$ & 1300 \\
\hline 3 & $60^{\circ} 20^{\prime} 00^{\prime \prime} \mathrm{N}$ & $1^{\circ} 0^{\prime} 01^{\prime \prime} \mathrm{E}$ & 150 & $16: 14$ & $15 / 04 / 2012$ & 165 \\
\hline 3 & $60^{\circ} 20^{\prime} 00^{\prime \prime} \mathrm{N}$ & $1^{\circ} 0^{\prime} 00^{\prime \prime} \mathrm{E}$ & 150 & $16: 35$ & $15 / 04 / 2012$ & 165 \\
\hline 3 & $60^{\circ} 20^{\prime} 01^{\prime \prime} \mathrm{N}$ & $1^{\circ} 0^{\prime} 00^{\prime \prime} \mathrm{E}$ & 150 & 01:58 & $16 / 04 / 2012$ & 165 \\
\hline 3 & $60^{\circ} 20^{\prime} 01^{\prime \prime} \mathrm{N}$ & $1^{\circ} 0^{\prime} 00^{\prime \prime} \mathrm{E}$ & 150 & $02: 22$ & $16 / 04 / 2012$ & 165 \\
\hline 3 & $60^{\circ} 20^{\prime} 01^{\prime \prime} \mathrm{N}$ & $1^{\circ} 0^{\prime} 00^{\prime \prime} \mathrm{E}$ & 150 & 06:07 & $16 / 04 / 2012$ & 165 \\
\hline 3 & $60^{\circ} 20^{\prime} 01^{\prime \prime} \mathrm{N}$ & $1^{\circ} 0^{\prime} 00^{\prime \prime} \mathrm{E}$ & 150 & $06: 34$ & $16 / 04 / 2012$ & 165 \\
\hline 1 & $61^{\circ} 30^{\prime} 00^{\prime \prime} \mathrm{N}$ & $11^{\circ} 0^{\prime} 01^{\prime \prime} \mathrm{W}$ & 400 & $03: 34$ & $19 / 04 / 2012$ & 1350 \\
\hline 1 & $61^{\circ} 29^{\prime} 99^{\prime \prime} \mathrm{N}$ & $11^{\circ} 0^{\prime} 01^{\prime \prime} \mathrm{W}$ & 200 & $05: 03$ & 19/04/2012 & 1350 \\
\hline 1 & $61^{\circ} 29^{\prime} 99^{\prime \prime} \mathrm{N}$ & $11^{\circ} 0^{\prime} 01^{\prime \prime} \mathrm{W}$ & 200 & $05: 33$ & 19/04/2012 & 1350 \\
\hline 1 & $61^{\circ} 30^{\prime} 14^{\prime \prime} \mathrm{N}$ & $11^{\circ} 0^{\prime} 04^{\prime \prime} \mathrm{W}$ & 200 & $17: 26$ & $20 / 04 / 2012$ & 1350 \\
\hline 1 & $61^{\circ} 30^{\prime} 33^{\prime \prime} \mathrm{N}$ & $11^{\circ} 0^{\prime} 08^{\prime \prime} \mathrm{W}$ & 200 & $17: 55$ & $20 / 04 / 2012$ & 1350 \\
\hline 2 & $62^{\circ} 50^{\prime} 00^{\prime \prime} \mathrm{N}$ & $2^{\circ} 30^{\prime} 03^{\prime \prime} \mathrm{W}$ & 400 & $03: 14$ & $23 / 04 / 2012$ & 1300 \\
\hline 2 & $62^{\circ} 50^{\prime} 00^{\prime \prime} \mathrm{N}$ & $2^{\circ} 30^{\prime} 03^{\prime \prime} \mathrm{W}$ & 200 & $05: 18$ & 23/04/2012 & 1300 \\
\hline 2 & $62^{\circ} 50^{\prime} 00^{\prime \prime} \mathrm{N}$ & $2^{\circ} 30^{\prime} 04^{\prime \prime} \mathrm{W}$ & 200 & $05: 50$ & $23 / 04 / 2012$ & 1300 \\
\hline 2 & $62^{\circ} 50^{\prime} 00^{\prime \prime} \mathrm{N}$ & $2^{\circ} 30^{\prime} 00^{\prime \prime} \mathrm{W}$ & 200 & $17: 32$ & $23 / 04 / 2012$ & 1300 \\
\hline 2 & $62^{\circ} 50^{\prime} 00^{\prime \prime} \mathrm{N}$ & $2^{\circ} 30^{\prime} 01^{\prime \prime} \mathrm{W}$ & 200 & $18: 00$ & $23 / 04 / 2012$ & 1300 \\
\hline 1 & $61^{\circ} 29^{\prime} 99^{\prime \prime} \mathrm{N}$ & $10^{\circ} 59^{\prime} 97^{\prime \prime} \mathrm{W}$ & 200 & $17: 48$ & $28 / 04 / 2012$ & 1350 \\
\hline 1 & $61^{\circ} 29^{\prime} 99^{\prime \prime} \mathrm{N}$ & $10^{\circ} 59^{\prime} 97^{\prime \prime} \mathrm{W}$ & 200 & $18: 18$ & $28 / 04 / 2012$ & 1350 \\
\hline 1 & $61^{\circ} 29^{\prime} 99^{\prime \prime} \mathrm{N}$ & $10^{\circ} 59^{\prime} 98^{\prime \prime} \mathrm{W}$ & 400 & 01:58 & $29 / 04 / 2012$ & 1350 \\
\hline 1 & $61^{\circ} 29^{\prime} 99^{\prime \prime} \mathrm{N}$ & $10^{\circ} 59^{\prime} 98^{\prime \prime} \mathrm{W}$ & 200 & 05:07 & 29/04/2012 & 1350 \\
\hline 1 & $61^{\circ} 29^{\prime} 99^{\prime} \mathrm{N}$ & $10^{\circ} 59^{\prime} 98^{\prime \prime} \mathrm{W}$ & 200 & $05: 38$ & $29 / 04 / 2012$ & 1350 \\
\hline
\end{tabular}


Table 2. Continued.

\begin{tabular}{|c|c|c|c|c|c|c|}
\hline Station & Latitude & Longitude & $\begin{array}{r}\text { Sampling depth } \\
(\mathrm{m})\end{array}$ & $\begin{array}{r}\text { Time } \\
\text { (start, local) }\end{array}$ & Date & $\begin{array}{r}\text { Bottom depth } \\
(\mathrm{m})\end{array}$ \\
\hline \multicolumn{7}{|c|}{ Icelandic cruise } \\
\hline 241 & $64^{\circ} 20^{\prime} 36^{\prime \prime} \mathrm{N}$ & $28^{\circ} 58^{\prime} 86^{\prime \prime} \mathrm{W}$ & 400 & $04: 45$ & $16 / 05 / 2012$ & 1018 \\
\hline 246 & $65^{\circ} 50^{\prime} 23^{\prime \prime} \mathrm{N}$ & $25^{\circ} 59^{\prime} 73^{\prime \prime} \mathrm{W}$ & 200 & $21: 29$ & $16 / 05 / 2012$ & 217 \\
\hline 248 & $66^{\circ} 1^{\prime} 22^{\prime \prime} \mathrm{N}$ & $26^{\circ} 47^{\prime} 73^{\prime \prime} \mathrm{W}$ & 400 & $01: 36$ & $17 / 05 / 2012$ & 450 \\
\hline 255 & $67^{\circ} 35^{\prime} 06^{\prime \prime} \mathrm{N}$ & $23^{\circ} 56^{\prime} 66^{\prime \prime} \mathrm{W}$ & 200 & $22: 22$ & $17 / 05 / 2012$ & 990 \\
\hline 267 & $66^{\circ} 44^{\prime} 11^{\prime \prime} \mathrm{N}$ & $18^{\circ} 52^{\prime} 16^{\prime \prime} \mathrm{W}$ & 200 & $23: 32$ & $18 / 05 / 2013$ & 698 \\
\hline 272 & $68^{\circ} 00^{\prime} 11^{\prime \prime} \mathrm{N}$ & $16^{\circ} 14^{\prime} 88^{\prime \prime} \mathrm{W}$ & 200 & $15: 24$ & $19 / 05 / 2012$ & 1271 \\
\hline 273 & $67^{\circ} 44^{\prime} 83^{\prime \prime} \mathrm{N}$ & $16^{\circ} 15^{\prime} 32^{\prime \prime} \mathrm{W}$ & 200 & $17: 57$ & $19 / 05 / 2012$ & 963 \\
\hline 274 & $67^{\circ} 29^{\prime} 91^{\prime \prime} \mathrm{N}$ & $16^{\circ} 15^{\prime} 21^{\prime \prime} \mathrm{W}$ & 200 & $19: 57$ & $19 / 05 / 2012$ & 805 \\
\hline 281 & $67^{\circ} 14^{\prime} 79^{\prime \prime} \mathrm{N}$ & $13^{\circ} 34^{\prime} 41^{\prime \prime} \mathrm{W}$ & 200 & $14: 08$ & $20 / 05 / 2012$ & 1540 \\
\hline 290 & $66^{\circ} 21^{\prime} 49^{\prime \prime} \mathrm{N}$ & $12^{\circ} 05^{\prime} 66^{\prime \prime} \mathrm{W}$ & 200 & $22: 59$ & $21 / 05 / 2012$ & 1082 \\
\hline 292 & $66^{\circ} 21^{\prime} 73^{\prime \prime} \mathrm{N}$ & $13^{\circ} 35^{\prime} 04^{\prime \prime} \mathrm{W}$ & 200 & $04: 10$ & $22 / 05 / 2012$ & 261 \\
\hline 299 & $65^{\circ} 00^{\prime} 11^{\prime \prime} \mathrm{N}$ & $11^{\circ} 17^{\prime} 33^{\prime \prime} \mathrm{W}$ & 200 & $23: 51$ & $22 / 05 / 2012$ & 537 \\
\hline 305 & $63^{\circ} 39^{\prime} 98^{\prime \prime} \mathrm{N}$ & $13^{\circ} 40^{\prime} 52^{\prime \prime} \mathrm{W}$ & 200 & $22: 49$ & $23 / 05 / 2012$ & 1125 \\
\hline 307 & $63^{\circ} 52^{\prime} 11^{\prime \prime} \mathrm{N}$ & $14^{\circ} 07^{\prime} 97^{\prime \prime} \mathrm{W}$ & 200 & $02: 28$ & $24 / 05 / 2012$ & 210 \\
\hline 315 & $63^{\circ} 07^{\prime} 23^{\prime \prime} \mathrm{N}$ & $19^{\circ} 54^{\prime} 72^{\prime \prime} \mathrm{W}$ & 200 & $02: 18$ & $25 / 05 / 2012$ & 1079 \\
\hline 324 & $62^{\circ} 58^{\prime} 09^{\prime \prime} \mathrm{N}$ & $21^{\circ} 29^{\prime} 99^{\prime \prime} \mathrm{W}$ & 400 & $03: 57$ & $26 / 05 / 2012$ & 990 \\
\hline 324 & $62^{\circ} 58^{\prime} 09^{\prime \prime} \mathrm{N}$ & $21^{\circ} 29^{\prime} 99^{\prime \prime} \mathrm{W}$ & 200 & 02:07 & $26 / 05 / 2012$ & 990 \\
\hline 330 & $63^{\circ} 03^{\prime} 38^{\prime \prime} \mathrm{N}$ & $23^{\circ} 04^{\prime} 65^{\prime \prime} \mathrm{W}$ & 200 & $19: 36$ & $26 / 05 / 2012$ & 896 \\
\hline 332 & $62^{\circ} 43^{\prime} 05^{\prime \prime} \mathrm{N}$ & $23^{\circ} 47^{\prime} 22^{\prime \prime} \mathrm{W}$ & 200 & $00: 17$ & $27 / 05 / 2012$ & 1253 \\
\hline 333 & $62^{\circ} 51^{\prime} 57^{\prime \prime} \mathrm{N}$ & $24^{\circ} 13^{\prime} 97^{\prime \prime} \mathrm{W}$ & 200 & $02: 54$ & $27 / 05 / 2012$ & 707 \\
\hline 338 & $63^{\circ} 17^{\prime} 02^{\prime \prime} \mathrm{N}$ & $25^{\circ} 37^{\prime} 37^{\prime \prime} \mathrm{W}$ & 200 & $15: 42$ & $27 / 05 / 2012$ & 620 \\
\hline 340 & $63^{\circ} 38^{\prime} 81^{\prime \prime} \mathrm{N}$ & $24^{\circ} 50^{\prime} 49^{\prime \prime} \mathrm{W}$ & 200 & $20: 35$ & $27 / 05 / 2012$ & 463 \\
\hline \multicolumn{7}{|l|}{ G.O. Sars } \\
\hline 152 & $62^{\circ} 25^{\prime} 00^{\prime \prime} \mathrm{N}$ & $5^{\circ} 4^{\prime} 23^{\prime \prime} \mathrm{E}$ & 200 & $22: 30$ & $03 / 05 / 2013$ & 212 \\
\hline 155 & $65^{\circ} 3^{\prime} 33^{\prime \prime} \mathrm{N}$ & $0^{\circ} 51^{\prime} 29^{\prime \prime} \mathrm{W}$ & 200 & $15: 45$ & $05 / 05 / 2013$ & 2912 \\
\hline 157 & $65^{\circ} 45^{\prime} 86^{\prime \prime} \mathrm{N}$ & $3^{\circ} 25^{\prime} 04^{\prime \prime} \mathrm{W}$ & 200 & 08:40 & $06 / 05 / 2013$ & 3200 \\
\hline 159 & $65^{\circ} 40^{\prime} 10^{\prime \prime} \mathrm{N}$ & $3^{\circ} 8^{\prime} 61^{\prime \prime} \mathrm{W}$ & 200 & $19: 50$ & $07 / 05 / 2013$ & 3693 \\
\hline 160 & $66^{\circ} 40^{\prime} 30^{\prime \prime} \mathrm{N}$ & $7^{\circ} 41^{\prime} 12^{\prime \prime} \mathrm{W}$ & 200 & $12: 00$ & $08 / 05 / 2013$ & 1783 \\
\hline 160bis & $66^{\circ} 29^{\prime} 59^{\prime \prime} \mathrm{N}$ & $8^{\circ} 24^{\prime} 14^{\prime \prime} \mathrm{W}$ & 200 & 23:01 & $08 / 05 / 2013$ & NA \\
\hline 161 & $67^{\circ} 3^{\prime} 28^{\prime \prime} \mathrm{N}$ & $9^{\circ} 54^{\prime} 45^{\prime \prime} \mathrm{W}$ & 200 & $11: 10$ & $09 / 05 / 2013$ & 1498 \\
\hline 162 & $67^{\circ} 33^{\prime} 80^{\prime \prime} \mathrm{N}$ & $12^{\circ} 29^{\prime} 71^{\prime \prime} \mathrm{W}$ & 200 & 09:20 & $10 / 05 / 2013$ & 1756 \\
\hline 163 & $68^{\circ} 8^{\prime} 94^{\prime \prime} \mathrm{N}$ & $15^{\circ} 10^{\prime} 16^{\prime \prime} \mathrm{W}$ & 200 & $11: 50$ & $11 / 05 / 2013$ & 1376 \\
\hline 165 & $68^{\circ} 47^{\prime} 65^{\prime \prime} \mathrm{N}$ & $18^{\circ} 21^{\prime} 56^{\prime \prime} \mathrm{W}$ & 200 & $02: 30$ & $12 / 05 / 2013$ & 1098 \\
\hline 166 & $63^{\circ} 29^{\prime} 98^{\prime \prime} \mathrm{N}$ & $24^{\circ} 10^{\prime} 18^{\prime \prime} \mathrm{W}$ & 200 & $00: 40$ & $14 / 05 / 2013$ & 224 \\
\hline 167 & $63^{\circ} 18^{\prime} 37^{\prime \prime} \mathrm{N}$ & $25^{\circ} 20^{\prime} 62^{\prime \prime} \mathrm{W}$ & 200 & $06: 40$ & $15 / 05 / 2013$ & 315 \\
\hline 168 & $62^{\circ} 32^{\prime} 05^{\prime \prime} \mathrm{N}$ & $28^{\circ} 5^{\prime} 90^{\prime \prime} \mathrm{W}$ & 200 & $19: 25$ & $15 / 05 / 2013$ & 1439 \\
\hline 169 & $61^{\circ} 32^{\prime} 71^{\prime \prime} \mathrm{N}$ & $32^{\circ} 31^{\prime} 04^{\prime \prime} \mathrm{W}$ & 200 & $16: 25$ & $16 / 05 / 2013$ & 2829 \\
\hline 170 & $60^{\circ} 31^{\prime} 13^{\prime \prime} \mathrm{N}$ & $36^{\circ} 27^{\prime} 64^{\prime \prime} \mathrm{W}$ & 200 & $19: 35$ & $17 / 05 / 2013$ & 2860 \\
\hline 171 & $59^{\circ} 22^{\prime} 83^{\prime \prime} \mathrm{N}$ & $46^{\circ} 11^{\prime} 59^{\prime \prime} \mathrm{W}$ & 200 & $14: 50$ & $20 / 05 / 2013$ & 1100 \\
\hline
\end{tabular}

\subsection{Genetic analysis of jellyfish}

\subsubsection{DNA extraction from CPR samples preserved in formaldehyde}

Jellyfish DNA collected from CPR samples was extracted using three different standard protocols.

Protocol 1 followed the methodology developed by Kirby et al. (2006). Briefly, small pieces of tissue from individual specimens (approximately $1 \mathrm{~mm}$ length) were placed individually into $180 \mu \mathrm{L}$ of Chelex solution (Instagene Matrix, Biorad) together with $6 \mu \mathrm{L}$ of $1 \mathrm{M}$ dithiothreitol (DTT), $4 \mu \mathrm{L}$ of proteinase $\mathrm{K}\left(10 \mathrm{mg} \mathrm{mL}^{-1}\right)$ and $10 \mu \mathrm{L}$ of $10 \%$ SDS and incubated at $55^{\circ} \mathrm{C}$ for $4 \mathrm{~h}$. Each sample was then vortexed briefly and centrifuged at $12000 \mathrm{~g}$ for $15 \mathrm{~s}$. Samples were then heated at $105^{\circ} \mathrm{C}$ for $10 \mathrm{~min}$ in a dry-block heater, vortexed for $10 \mathrm{~s}$ and centrifuged at $12000 \mathrm{~g}$ for $3 \mathrm{~min}$. The supernatant was then transferred to a Micropure-EZ centrifugal filter device (CFD) (Millipore Corp.) inserted into a Microcon YM-30 CFD (Millipore Corp.) and centrifuged at $14000 \mathrm{~g}$ for $8 \mathrm{~min}$. After the Micropure-EZ CFD was discarded, the sample retained in the YM-30 was washed three times with $200 \mu \mathrm{L}$ of sterile water; the first two washes were 
Table 3. List of stations at which jellyfish were collected using different collection gears. Main sampling information is also indicated. Data from Licandro (2014a, b), Licandro and Hosia (2014) and Licandro et al. (2014).

\begin{tabular}{|c|c|c|c|c|c|}
\hline Station & Latitude & Longitude & $\begin{array}{l}\text { Sampling depths } \\
\text { (m) }\end{array}$ & $\begin{array}{r}\text { Time } \\
\text { (start, local) }\end{array}$ & Date \\
\hline \multicolumn{6}{|c|}{ G.O. Sars cruise } \\
\hline \multicolumn{6}{|c|}{ MOCNESS } \\
\hline 152 & $62^{\circ} 25^{\prime} 00^{\prime \prime} \mathrm{N}$ & $5^{\circ} 4^{\prime} 23^{\prime \prime} \mathrm{E}$ & $0: 25: 50: 100$ & $18: 50$ & $03 / 05 / 2013$ \\
\hline 154 & $64^{\circ} 8^{\prime} 4^{\prime \prime} \mathrm{N}$ & $1^{\circ} 33^{\prime} 39^{\prime \prime} \mathrm{E}$ & $\begin{array}{l}0: 25: 50: 100: 200: 400: 600: 800: \\
1000\end{array}$ & 19:01 & $04 / 05 / 2013$ \\
\hline 155 & $65^{\circ} 3^{\prime} 33^{\prime \prime} \mathrm{N}$ & $0^{\circ} 51^{\prime} 29^{\prime \prime} \mathrm{W}$ & $200: 400: 600: 800: 1000$ & $05: 12$ & $05 / 05 / 2013$ \\
\hline 157 & $65^{\circ} 40^{\prime} 72^{\prime \prime} \mathrm{N}$ & $2^{\circ} 59^{\prime} 06^{\prime \prime} \mathrm{W}$ & $50: 100: 200: 400: 600: 800: 1000$ & $04: 22$ & $07 / 05 / 2013$ \\
\hline 160 & $66^{\circ} 39^{\prime} 52^{\prime \prime} \mathrm{N}$ & $7^{\circ} 38^{\prime} 86^{\prime \prime} \mathrm{W}$ & $0: 25: 50 / 200: 400: 600: 800: 1000$ & $06: 27$ & $08 / 05 / 2013$ \\
\hline 161 & $67^{\circ} 1^{\prime} 39^{\prime \prime} \mathrm{N}$ & $9^{\circ} 45^{\prime} 32^{\prime \prime} \mathrm{W}$ & $\begin{array}{l}0: 25: 50: 100: 200 / 400: 600: 800: \\
100\end{array}$ & 05:59 & $09 / 05 / 2013$ \\
\hline 162 & $67^{\circ} 33^{\prime} 83^{\prime \prime} \mathrm{N}$ & $12^{\circ} 29^{\prime} 88^{\prime \prime} \mathrm{W}$ & $\begin{array}{l}0: 25: 50: 100: 200: 400: 600: 800: \\
1000\end{array}$ & 08:31 & $10 / 05 / 2013$ \\
\hline 163 & $68^{\circ} 8^{\prime} 86^{\prime \prime} \mathrm{N}$ & $15^{\circ} 9^{\prime} 44^{\prime \prime} \mathrm{W}$ & $\begin{array}{l}0: 25: 50: 100: 200: 400: 600: 800: \\
1000\end{array}$ & 06:18 & $11 / 05 / 2013$ \\
\hline 167 & $63^{\circ} 32^{\prime} 09^{\prime \prime} \mathrm{N}$ & $25^{\circ} 32^{\prime} 21^{\prime \prime} \mathrm{W}$ & $0: 25: 50: 100: 200: 300$ & $03: 22$ & $15 / 05 / 2013$ \\
\hline 168 & $62^{\circ} 52^{\prime} 75^{\prime \prime} \mathrm{N}$ & $28^{\circ} 11^{\prime} 62^{\prime \prime} \mathrm{W}$ & $0: 25: 50: 100: 200 /$ & $18: 33$ & $15 / 05 / 2013$ \\
\hline 169 & $61^{\circ} 56^{\prime} 90^{\prime \prime} \mathrm{N}$ & $32^{\circ} 41^{\prime} 45^{\prime \prime} \mathrm{W}$ & $\begin{array}{l}0: 25: 50: 100: 200: 400 / 600: 800: \\
1000\end{array}$ & 10:02 & $16 / 05 / 2013$ \\
\hline 170 & $60^{\circ} 54^{\prime} 61^{\prime \prime} \mathrm{N}$ & $36^{\circ} 53^{\prime} 51^{\prime \prime} \mathrm{W}$ & $0: 25: 50: 100: 200: 400 / 800: 1000$ & $12: 37$ & $17 / 05 / 2013$ \\
\hline 171 & $59^{\circ} 46^{\prime} 97^{\prime \prime} \mathrm{N}$ & $46^{\circ} 39^{\prime} 50^{\prime \prime} \mathrm{W}$ & $50: 100: 200: 400: 600: 800: 1000$ & $18: 34$ & $20 / 05 / 2013$ \\
\hline \multicolumn{6}{|c|}{ Macroplankton trawl } \\
\hline 101 & $65^{\circ} 9^{\prime} 30^{\prime \prime} \mathrm{N}$ & $0^{\circ} 48^{\prime} 44^{\prime \prime} \mathrm{W}$ & $290-310$ & $17: 24$ & $05 / 05 / 2013$ \\
\hline 102 & $65^{\circ} 15^{\prime} 82^{\prime \prime} \mathrm{N}$ & $0^{\circ} 54^{\prime} 43^{\prime \prime} \mathrm{W}$ & $0-700$ & $15: 45$ & $05 / 05 / 2013$ \\
\hline 104 & $65^{\circ} 39^{\prime} 70^{\prime \prime} \mathrm{N}$ & $2^{\circ} 53^{\prime} 58^{\prime \prime} \mathrm{W}$ & $0-1028$ & $01: 58$ & $07 / 05 / 2013$ \\
\hline 105 & $65^{\circ} 50^{\prime} 63^{\prime \prime} \mathrm{N}$ & $3^{\circ} 54^{\prime} 6^{\prime \prime} \mathrm{W}$ & 500 & $18: 39$ & $07 / 05 / 2013$ \\
\hline 106 & $66^{\circ} 43^{\prime} 66^{\prime \prime} \mathrm{N}$ & $7^{\circ} 51^{\prime} 16^{\prime \prime} \mathrm{W}$ & $0-1000$ & $11: 44$ & $08 / 05 / 2013$ \\
\hline 107 & $67^{\circ} 4^{\prime} 08^{\prime \prime} \mathrm{N}$ & $9^{\circ} 57^{\prime} 89^{\prime \prime} \mathrm{W}$ & $40-70$ & $10: 49$ & $09 / 05 / 2013$ \\
\hline 108 & $67^{\circ} 36^{\prime} 33^{\prime \prime} \mathrm{N}$ & $12^{\circ} 39^{\prime} 26^{\prime \prime} \mathrm{W}$ & $30-38$ & $10: 52$ & $10 / 05 / 2013$ \\
\hline 109 & $67^{\circ} 40^{\prime} 12^{\prime \prime} \mathrm{N}$ & $12^{\circ} 56^{\prime} 20^{\prime \prime} \mathrm{W}$ & $400-420$ & $13: 08$ & $10 / 05 / 2013$ \\
\hline 111 & $68^{\circ} 11^{\prime} 49^{\prime \prime} \mathrm{N}$ & $15^{\circ} 24^{\prime} 08^{\prime \prime} \mathrm{W}$ & $0-1000$ & $11: 35$ & $11 / 05 / 2013$ \\
\hline 115 & $63^{\circ} 29^{\prime} 41^{\prime \prime} \mathrm{N}$ & $25^{\circ} 37^{\prime} 58^{\prime \prime} \mathrm{W}$ & $120-150$ & $06: 24$ & $15 / 05 / 2013$ \\
\hline 116 & $63^{\circ} 0^{\prime} 77^{\prime \prime} \mathrm{N}$ & $27^{\circ} 54^{\prime} 33^{\prime \prime} \mathrm{W}$ & 460 & $13: 25$ & $15 / 05 / 2013$ \\
\hline 117 & $62^{\circ} 56^{\prime} 56^{\prime \prime} \mathrm{N}$ & $28^{\circ} 3^{\prime} 49^{\prime \prime} \mathrm{W}$ & 250 & $15: 16$ & $15 / 05 / 2013$ \\
\hline 118 & $61^{\circ} 54^{\prime} 55^{\prime \prime} \mathrm{N}$ & $32^{\circ} 55^{\prime} 85^{\prime \prime} \mathrm{W}$ & $490-500$ & $16: 31$ & $16 / 05 / 2013$ \\
\hline 120 & $61^{\circ} 50^{\prime} 58^{\prime \prime} \mathrm{N}$ & $33^{\circ} 16^{\prime} 67^{\prime \prime} \mathrm{W}$ & $0-1000$ & $20: 31$ & $16 / 05 / 2013$ \\
\hline 121 & $61^{\circ} 49^{\prime} 10^{\prime \prime} \mathrm{N}$ & $33^{\circ} 25^{\prime} 60^{\prime \prime} \mathrm{W}$ & $695-705$ & $22: 14$ & $16 / 05 / 2013$ \\
\hline 122 & $60^{\circ} 51^{\prime} 58^{\prime \prime} \mathrm{N}$ & $36^{\circ} 48^{\prime} 78^{\prime \prime} \mathrm{W}$ & $510-520$ & $19: 05$ & $17 / 05 / 2013$ \\
\hline 123 & $60^{\circ} 51^{\prime} 36^{\prime \prime} \mathrm{N}$ & $36^{\circ} 58^{\prime} 74^{\prime \prime} \mathrm{W}$ & $320-330$ & $20: 55$ & $17 / 05 / 2013$ \\
\hline 124 & $60^{\circ} 51^{\prime} 37^{\prime \prime} \mathrm{N}$ & $37^{\circ} 8^{\prime} 65^{\prime \prime} \mathrm{W}$ & $630-660$ & $23: 40$ & $17 / 05 / 2013$ \\
\hline 125 & $59^{\circ} 38^{\prime} 80^{\prime \prime} \mathrm{N}$ & $46^{\circ} 23^{\prime} 12^{\prime \prime} \mathrm{W}$ & $170-200$ & $14: 13$ & $20 / 05 / 2013$ \\
\hline 126 & $59^{\circ} 40^{\prime} 64^{\prime \prime} \mathrm{N}$ & $46^{\circ} 29^{\prime} 94^{\prime \prime} \mathrm{W}$ & 380 & $15: 33$ & $20 / 05 / 2013$ \\
\hline 127 & $59^{\circ} 43^{\prime} 89^{\prime \prime} \mathrm{N}$ & $46^{\circ} 34^{\prime} 73^{\prime \prime} \mathrm{W}$ & $0-1000$ & $16: 55$ & $20 / 05 / 2013$ \\
\hline \multicolumn{6}{|c|}{ IEO data set } \\
\hline \multicolumn{6}{|c|}{ Bongo net } \\
\hline TF-01 & $36^{\circ} 8^{\prime} 76^{\prime \prime} \mathrm{N}$ & $6^{\circ} 0^{\prime} 96^{\prime \prime} \mathrm{W}$ & 29 & $20: 05$ & $04 / 03 / 2010$ \\
\hline SP-01 & $36^{\circ} 22^{\prime} 26^{\prime \prime} \mathrm{N}$ & $6^{\circ} 16^{\prime} 44^{\prime \prime} \mathrm{W}$ & 22 & $03: 28$ & $06 / 03 / 2010$ \\
\hline GD-01 & $36^{\circ} 44^{\prime} 70^{\prime \prime} \mathrm{N}$ & $6^{\circ} 29^{\prime} 76^{\prime \prime} \mathrm{W}$ & 16 & $01: 18$ & $07 / 03 / 2010$ \\
\hline SP-01 & $36^{\circ} 22^{\prime} 26^{\prime \prime} \mathrm{N}$ & $6^{\circ} 16^{\prime} 44^{\prime \prime} \mathrm{W}$ & 21 & $19: 22$ & $26 / 07 / 2010$ \\
\hline GD-02 & $36^{\circ} 43^{\prime} 08^{\prime \prime} \mathrm{N}$ & $6^{\circ} 32^{\prime} 46^{\prime \prime} \mathrm{W}$ & 16 & $21: 34$ & $27 / 07 / 2010$ \\
\hline GD-02 & $36^{\circ} 39^{\prime} 96^{\prime \prime} \mathrm{N}$ & $6^{\circ} 36^{\prime} 78^{\prime \prime} \mathrm{W}$ & 40 & $21: 24$ & $09 / 11 / 2010$ \\
\hline SP-01 & $36^{\circ} 24^{\prime} 72^{\prime \prime} \mathrm{N}$ & $6^{\circ} 18^{\prime} 06^{\prime \prime} \mathrm{W}$ & 27 & 03:00 & $11 / 11 / 2010$ \\
\hline TF-01 & $36^{\circ} 8^{\prime} 52^{\prime \prime} \mathrm{N}$ & $6^{\circ} 2^{\prime} 52^{\prime \prime} \mathrm{W}$ & 28 & $02: 18$ & $12 / 11 / 2010$ \\
\hline \multicolumn{6}{|c|}{ AZTI data set } \\
\hline \multicolumn{6}{|l|}{ Bongo net } \\
\hline 58 & $43^{\circ} 45^{\prime} \mathrm{N}$ & $5^{\circ} 15^{\prime} 15^{\prime \prime} \mathrm{W}$ & 220 & $12: 30$ & $22 / 05 / 2010$ \\
\hline 67 & $45^{\circ} 14^{\prime} 97^{\prime \prime} \mathrm{N}$ & $5^{\circ} 15^{\prime} 04^{\prime \prime} \mathrm{W}$ & 206 & $18: 51$ & $23 / 05 / 2010$ \\
\hline 68 & $45^{\circ} 45^{\prime} \mathrm{N}$ & $5^{\circ} 44^{\prime \prime} 72^{\prime \prime} \mathrm{W}$ & 208 & $11: 43$ & $24 / 05 / 2010$ \\
\hline 69 & $45^{\circ} 45^{\prime} 02^{\prime \prime} \mathrm{N}$ & $5^{\circ} 15^{\prime}, 18^{\prime \prime} \mathrm{W}$ & 209 & $02: 34$ & $24 / 05 / 2010$ \\
\hline
\end{tabular}




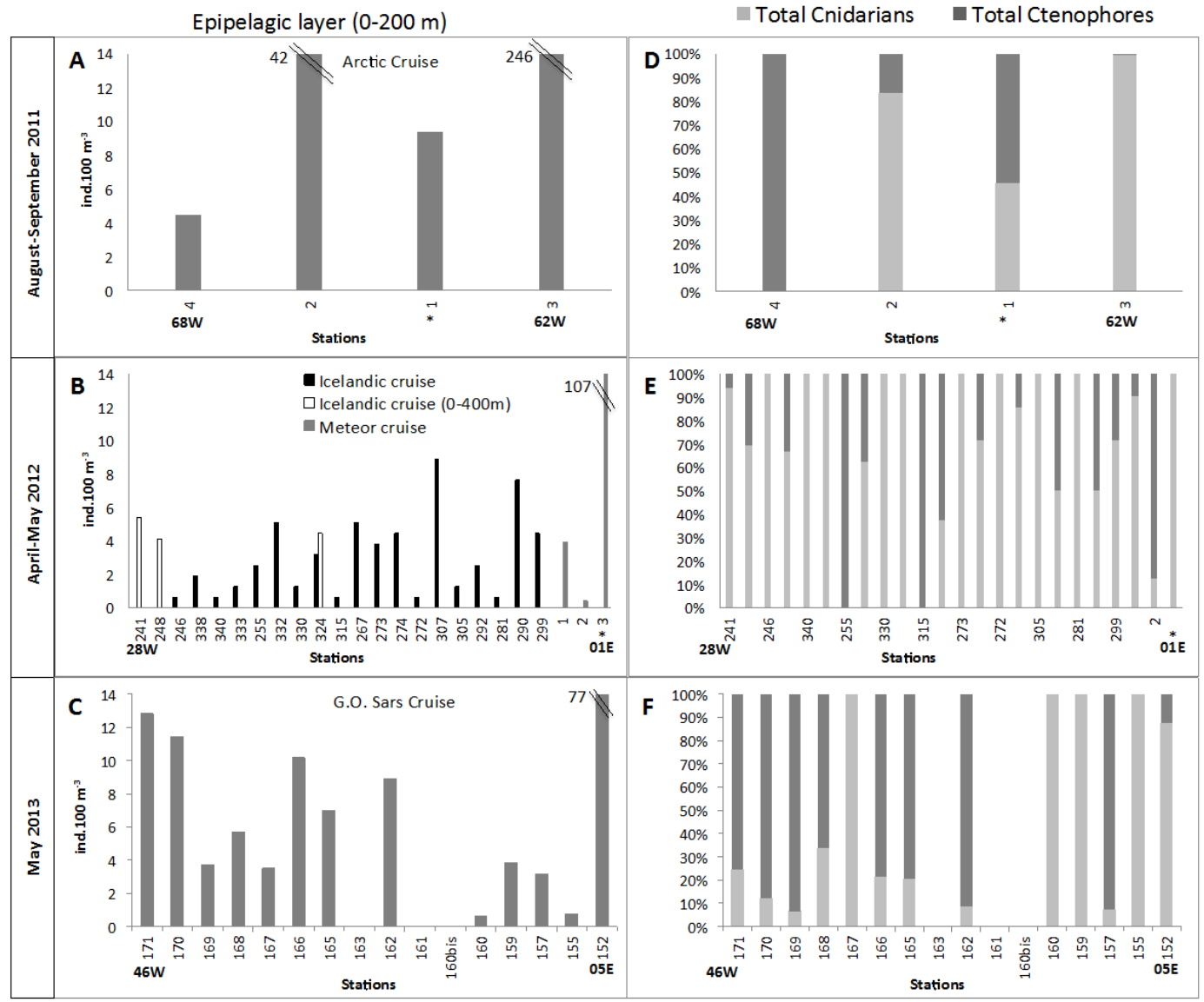

Figure 2. Total jellyfish abundance and relative proportion of Cnidaria and Ctenophora in the stations sampled during the Arctic cruise (a and $\mathbf{d}$ ), the Icelandic and Meteor cruise (b and e) and the G.O. Sars cruise (c and f).

centrifuged at $14000 \mathrm{~g}$ for $8 \mathrm{~min}$ and the final wash was centrifuged at $14000 \mathrm{~g}$ for $5 \mathrm{~min}$. The retained DNA was then recovered. All centrifugation steps were performed at $22^{\circ} \mathrm{C}$.

Protocol 2 consisted of washing the tissues samples in TE buffer then processing the sample either with the MasterPure total DNA and RNA extraction kit (Epicentre Biotechnologies, USA) using protocol B (tissue samples) with an extended proteinase K digestion step of $4-12 \mathrm{~h}$ or using DNAzol reagent (Life Technologies, USA) applying procedure for homogenisation of tissues with the optional centrifugation step as described by the manufacturers. DNA pellets were then dissolved in a final volume of $30 \mu \mathrm{L}$.

A third protocol was used to extract DNA from jellyfish material embedded in the silk. In this case, approximately one-third of a CPR sample was cut and washed in TE buffer and then total environmental DNA was extracted from it according to a phenol-chloroform-based protocol developed by Ripley et al. (2008).

A number of different polymerase chain reaction (PCR) amplification strategies and markers were used.

In one case, a 540 bp partial, mtDNA 16S rDNA sequence was amplified by PCR using the primers of Cunningham and
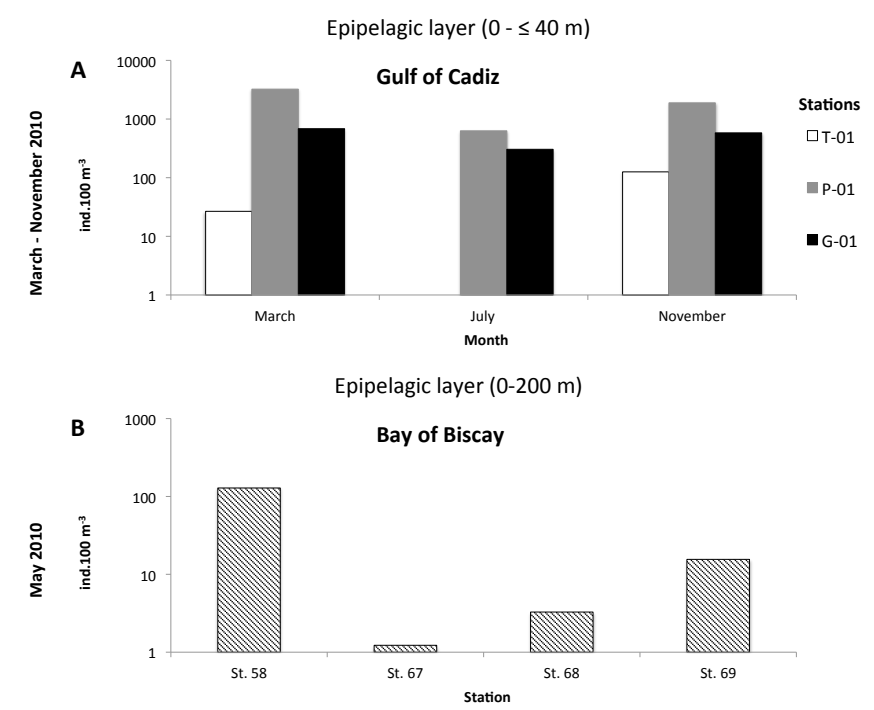

Figure 3. Total jellyfish abundance in the stations sampled in the Gulf of Cádiz (a) and in the Bay of Biscay (b). 
Table 4. Jellynet data set. List of jellyfish taxa collected in epipelagic waters $(0-200 \mathrm{~m})$ in different North Atlantic regions. *Taxon found only in samples collected at 0-400 m depth. Data from Licandro et al. (2014).

\begin{tabular}{|c|c|c|c|c|c|c|}
\hline North Atlantic region & Cumberland shelf & Labrador Sea & Irminger Sea & Norwegian/Icelandic Sea & Icelandic Sea & North of Scotland \\
\hline Stations & $1-4$ & 171 & $166-170$ & $152-165$ & $241-340$ & $1-3$ \\
\hline Cruise & Arctic & \multicolumn{3}{|c|}{ G.O. Sars cruise } & Icelandic & Meteor \\
\hline Latitude & $63-67^{\circ} \mathrm{N}$ & $59^{\circ} \mathrm{N}$ & $60-63^{\circ} \mathrm{N}$ & $62-68^{\circ} \mathrm{N}$ & $62-68^{\circ} \mathrm{N}$ & $60-62^{\circ} \mathrm{N}$ \\
\hline Longitude & $62-68^{\circ} \mathrm{W}$ & $46^{\circ} \mathrm{W}$ & $36-24^{\circ} \mathrm{W}$ & $18^{\circ} \mathrm{W}-5^{\circ} \mathrm{E}$ & $11-28^{\circ} \mathrm{W}$ & $2^{\circ} \mathrm{W}-1^{\circ} \mathrm{E}$ \\
\hline Time & Day/night & Day & Day/night & Day/night & Day/night & Day/night \\
\hline Date & 22 Aug-22 Sep 2011 & 20 May 2013 & 14-17 May 2013 & 3-12 Мay 2013 & 16-25 May 2012 & 9-29 Apr 2012 \\
\hline \multicolumn{7}{|l|}{ Cnidaria } \\
\hline \multicolumn{7}{|l|}{ Hydrozoa } \\
\hline \multicolumn{7}{|l|}{ Order Trachymedusae } \\
\hline \multicolumn{7}{|l|}{ Family Rhopalonematidae } \\
\hline Aglantha digitale & + & & + & + & + & + \\
\hline Pantachogon haeckeli & & + & & & & \\
\hline Pantachogon spp. & & + & & & & \\
\hline \multicolumn{7}{|l|}{ Order Narcomedusae } \\
\hline \multicolumn{7}{|l|}{ Family Aeginidae } \\
\hline Aeginopsis laurentii & + & & & & & \\
\hline \multicolumn{7}{|l|}{ Order Leptothecata } \\
\hline \multicolumn{7}{|l|}{ Family Phialellidae } \\
\hline Phialella quadrata & & & & & & + \\
\hline \multicolumn{7}{|l|}{ Family Mitrocomidae } \\
\hline Cosmetira pilosella & & & & + & & \\
\hline Mitrocomella polydiademata & & & & + & & \\
\hline \multicolumn{7}{|l|}{ Family Tiarannidae } \\
\hline Modeeria rotunda & & & & + & & \\
\hline \multicolumn{7}{|l|}{ Family Tiaropsidae } \\
\hline Tiaropsis multicirrata & & & & + & & \\
\hline \multicolumn{7}{|l|}{ Family Campanulariidae } \\
\hline Clytia islandica & & & & + & & \\
\hline Clytia spp. & & & & + & + & + \\
\hline Obelia spp. & & & & + & & + \\
\hline \multicolumn{7}{|l|}{ Order Siphonophorae } \\
\hline \multicolumn{7}{|l|}{ Suborder Physonectae } \\
\hline Physonectae larva & & & & + & & + \\
\hline \multicolumn{7}{|l|}{ Family Agalmatidae } \\
\hline Agalma elegans & & & & & & + \\
\hline Nanomia cara & & & + & + & + & + \\
\hline Family Physophoridae & & & & & & \\
\hline Physophora hydrostatica & & & & & & + \\
\hline Suborder Calycophorae & & & & & & \\
\hline Family Diphyidae & & & & & & \\
\hline Dimophyes arctica & + & + & + & & & + \\
\hline Lensia achilles & & & & + & $+*$ & \\
\hline Lensia conoidea & & & & & + & + \\
\hline Lensia spp. & & & & + & + & + \\
\hline Muggiaea atlantica & & & & & & + \\
\hline Family Clausophyidae & & & & & & \\
\hline Chuniphyes multidentata & & & & & $+*$ & + \\
\hline Order Anthoathecata & & & & & & \\
\hline Family Corymorphidae & & & & & & \\
\hline Euphysa aurata & & & & & & + \\
\hline Aplanulata incerta sedis & & & & & & \\
\hline Plotocnide borealis & & & & & & + \\
\hline Family Rathkeidae & & & & & & \\
\hline Rathkea octopunctata & & & & & & + \\
\hline Lizzia blondina & & & & & & + \\
\hline Family Pandeidae & & & & & & \\
\hline Amphinema rugosum & & & & & & + \\
\hline Family Zancleidae & & & & & & \\
\hline Zanclea spp. & & & + & & & \\
\hline
\end{tabular}


Table 4. Continued.

\begin{tabular}{|c|c|c|c|c|c|c|}
\hline North Atlantic region & Cumberland shelf & Labrador Sea & Irminger Sea & Norwegian/Icelandic Sea & Icelandic Sea & North of Scotland \\
\hline Stations & $1-4$ & 171 & $166-170$ & $152-165$ & $241-340$ & $1-3$ \\
\hline Cruise & Arctic & \multicolumn{3}{|c|}{ G.O. Sars cruise } & Icelandic & Meteor \\
\hline Latitude & $63-67^{\circ} \mathrm{N}$ & $59^{\circ} \mathrm{N}$ & $60-63^{\circ} \mathrm{N}$ & $62-68^{\circ} \mathrm{N}$ & $62-68^{\circ} \mathrm{N}$ & $60-62^{\circ} \mathrm{N}$ \\
\hline Longitude & $62-68^{\circ} \mathrm{W}$ & $46^{\circ} \mathrm{W}$ & $36-24^{\circ} \mathrm{W}$ & $18^{\circ} \mathrm{W}-5^{\circ} \mathrm{E}$ & $11-28^{\circ} \mathrm{W}$ & $2^{\circ} \mathrm{W}-1^{\circ} \mathrm{E}$ \\
\hline Time & Day/night & Day & Day/night & Day/night & Day/night & Day/night \\
\hline Date & 22 Aug-22 Sep 2011 & 20 May 2013 & 14-17 May 2013 & 3-12 May 2013 & 16-25 May 2012 & 9-29 Apr 2012 \\
\hline \multicolumn{7}{|l|}{ Ctenophora } \\
\hline \multicolumn{7}{|l|}{ Order Cydippida } \\
\hline Cydippida larva & & & + & + & & \\
\hline \multicolumn{7}{|l|}{ Family Mertensiidae } \\
\hline Mertensia ovum & + & + & & & & \\
\hline Mertensiidae spp. & & + & & & + & \\
\hline \multicolumn{7}{|l|}{ Order Beroida } \\
\hline \multicolumn{7}{|l|}{ Family Beroidae } \\
\hline Beroe cucumis & & & + & + & + & + \\
\hline Beroe gracilis & & & + & & & + \\
\hline Beroe spp. & + & + & & + & + & + \\
\hline Bolinopsis infundibulum & & & & + & & \\
\hline
\end{tabular}

Buss (1993) and Schroth et al. (2002). The PCR involved an initial denaturation step at $94^{\circ} \mathrm{C}(1 \mathrm{~min})$, followed by 40 or 50 cycles of $94(1 \mathrm{~min}), 51(1 \mathrm{~min})$ and $72^{\circ} \mathrm{C}(1 \mathrm{~min})$ and a final extension of $72^{\circ} \mathrm{C}(10 \mathrm{~min})$.

The PCR products were visualised on a $1 \%$ agarose gel and either purified using Montage spin columns (Millipore) or treated with ExoSAPIT (Illustra, supplied by VWR) to remove primer dimers. Purified PCR products were then sequenced commercially (MWG Biotech, Germany, or Source Bioscience, Nottingham, UK) using the amplification primers as sequencing primers. Alternatively Sanger sequencing of PCR products was performed using a BigDye kit (Applied Biosystems, USA), with either the forward or reverse primer for amplification, according to manufacturer instructions and capillary electrophoresis of sequencing products carried out at Source Bioscience.

\subsubsection{DNA extraction from net samples preserved in ethanol}

Jellyfish DNA was extracted from about 80 ethanolpreserved cnidarian specimens, which were collected during the EURO-BASIN cruises and identified on board or shortly after collection. DNA extraction followed a standard SDS, proteinase $\mathrm{K}$, phenol-chloroform protocol. Briefly, $\sim 1 \mathrm{~mm}^{3}$ of jellyfish tissue was placed into a $1.5 \mathrm{~mL}$ Eppendorf tube containing $400 \mu \mathrm{L}$ cell lysis buffer $(10 \mathrm{mM}$ Tris- $\mathrm{Cl} \mathrm{pH}$ 7.9, $100 \mathrm{mM}$ EDTA and $0.5 \%$ SDS) with $4 \mu \mathrm{L}$ of proteinase K solution $\left(10 \mathrm{mg} \mathrm{mL}^{-1}\right)$ and digested for $4 \mathrm{~h}$ at $55^{\circ} \mathrm{C}$. Following a phenol-chloroform purification the DNA was recovered by precipitation using $\mathrm{NaCl}$ and $\mathrm{EtOH}$ and resuspended in $40 \mu \mathrm{L}$ of nanopure $\mathrm{H}_{2} \mathrm{O}$. A $1 \mu \mathrm{L}$ aliquot of the extracted DNA was then used as template in a PCR.

A 540 bp partial, mtDNA $16 \mathrm{~S}$ rDNA sequence was then amplified by PCR using the primers of Cunningham and
Buss (1993) and Schroth et al. (2002) and the thermal profile described above. PCR products were visualised on a $1 \%$ agarose gel and purified using Montage spin columns (Millipore). Purified PCR products were then sequenced commercially (MWG Biotech) using the amplification primers as sequencing primers.

Overall 23 cnidarian taxa were successfully sequenced and published on GenBank (Table 9).

\subsubsection{DNA sequence analysis}

Sequence identity of CPR cnidarian tissue was established first by comparison with public repositories and private databases of Cnidaria DNA sequences taken from plankton net samples in different regions of the North Atlantic. Further analysis was performed by aligning DNA sequences with Cnidaria sequences from public databases for the same DNA marker using Bioedit (Hall et al., 1999). These were trimmed and exported into MEGA 5.1 (Katoh et al., 1995) to produce phylogenies using neighbour-joining methods with a Kimura two-parameter substitution model and tested using 1000 bootstrap confidence intervals.

\section{Results}

\subsection{Jellyfish abundance and diversity in epipelagic waters}

\subsubsection{Jellynet data}

The data collected in epipelagic waters between 2011 and 2013 showed high variability in jellyfish standing stocks across the northern North Atlantic Basin (Fig. 2). Total jellyfish abundance (Fig. 2a-c) generally ranged between 0.42 and 12 individuals $100 \mathrm{~m}^{-3}$. A few stations located on the 
eastern (i.e. station 3, Meteor cruise; station 152, G.O. Sars cruise) and western (stations 1 and 2, Arctic cruise) Atlantic shelves exhibited elevated abundance with densities an order of magnitude greater (max. 246 individuals $100 \mathrm{~m}^{-3}$ ).

In the 0-200 m layer, cnidarians were typically more abundant than ctenophores (Fig. 2d-f), even though in some stations (station 4, Arctic cruise; stations 255 and 315, Icelandic cruise; station 162, G.O. Sars cruise) ctenophores made up $90-100 \%$ of the total jellyfish abundance.

Overall 27 cnidarian and 5 ctenophore taxa were identified and counted in North Atlantic epipelagic waters (Table 4). Jellyfish populations were more diversified in the northeastern Atlantic, mainly due to the presence of meroplanktonic species of Anthomedusae and Leptomedusae. The trachymedusa Aglantha digitale, the siphonophores Nanomia cara and Dimophyes arctica, and the ctenophores Beroe spp. and Mertensidae were the most common taxa in epipelagic waters across the northern North Atlantic region.

\subsubsection{Bongo data}

In shallow waters in the Gulf of Cádiz, jellyfish distribution was highly variable in space and time. They were relatively more abundant in early spring and autumn (Fig. 3a), with high peaks due to swarms of the siphonophores Muggiaea atlantica and Muggiaea kochi (not shown). Generally only cnidarians were found in the samples (Table 5), except in March 2010, when the ctenophore Hormiphora spp. represented 11 and $63 \%$ of the total jellyfish abundance respectively at stations P-01 and G-01 (not shown).

Jellyfish species typically distributed in cold-temperate and warm-water regions were recorded in the Bay of Biscay (Table 5). Their densities in May 2010 suggest that jellyfish are less abundant in this region than in the Gulf of Cádiz (Fig. 3b), even though this should be further verified.

\subsection{Jellyfish abundance and diversity in the $0-1000 \mathrm{~m}$ layer}

\subsubsection{MOCNESS data}

The data collected at different depths in the $0-1000 \mathrm{~m}$ layer during the G.O. Sars cruise show that in early May 2013 the bulk of the jellyfish population was concentrated in the mesopelagic layer (200-1000 m depth) off the Norwegian trench and in the Icelandic Sea (Fig. 4). In contrast, in the Irminger and Labrador seas, jellyfish were more evenly distributed across the water column or mainly concentrated close to the surface (Fig. 4).

Species diversity was generally higher in the mesopelagic than in the epipelagic layer (Fig. 5), with the highest number of species being recorded below $400 \mathrm{~m}$ in the Irminger and Labrador seas.
Table 5. Bongo net data set. List of jellyfish taxa collected in epipelagic waters (0-200 m or 0-bottom) in 2010, in the Gulf of Cádiz and Bay of Biscay. Data from Licandro et al. (2014).

\begin{tabular}{|c|c|c|}
\hline North Atlantic region & Gulf of Cádiz & Bay of Biscay \\
\hline Latitude & $36^{\circ} \mathrm{N}$ & $43-45^{\circ} \mathrm{N}$ \\
\hline Longitude & $6^{\circ} \mathrm{W}$ & $5^{\circ} \mathrm{W}$ \\
\hline Maximum sampling depth (m) & $16-40$ & $206-220$ \\
\hline Time & Day/night & Day/night \\
\hline Month & $03,07,112010$ & 05,2010 \\
\hline \multicolumn{3}{|l|}{ Cnidaria } \\
\hline \multicolumn{3}{|l|}{ Hydrozoa } \\
\hline \multicolumn{3}{|l|}{ Order Trachymedusae } \\
\hline \multicolumn{3}{|l|}{ Family Geryoniidae } \\
\hline Liriope tetraphylla & + & + \\
\hline \multicolumn{3}{|l|}{ Family Rhopalonematidae } \\
\hline Aglaura hemistoma & + & \\
\hline Aglantha digitale & & + \\
\hline \multicolumn{3}{|l|}{ Order Leptothecata } \\
\hline \multicolumn{3}{|l|}{ Family Lovenellidae } \\
\hline Eucheilota paradoxica & + & \\
\hline \multicolumn{3}{|l|}{ Family Campanulariidae } \\
\hline Clytia hemisphaerica & + & \\
\hline Clytia spp. & + & \\
\hline Obelia spp. & + & \\
\hline \multicolumn{3}{|l|}{ Order Siphonophorae } \\
\hline \multicolumn{3}{|l|}{ Suborder Physonectae } \\
\hline Physonectae larva & + & \\
\hline \multicolumn{3}{|l|}{ Family Agalmatidae } \\
\hline Agalma elegans & & + \\
\hline \multicolumn{3}{|l|}{ Suborder Calycophorae } \\
\hline \multicolumn{3}{|l|}{ Family Abylidae } \\
\hline Abylopsis tetragona & + & \\
\hline Bassia bassensis & + & \\
\hline \multicolumn{3}{|l|}{ Family Diphyidae } \\
\hline Chelophyes appendiculata & + & + \\
\hline Eudoxoides spiralis & + & \\
\hline Lensia conoidea & & + \\
\hline Muggiaea atlantica & + & + \\
\hline Muggiaea kochi & + & + \\
\hline \multicolumn{3}{|l|}{ Order Anthoathecata } \\
\hline \multicolumn{3}{|l|}{ Family Coryniidae } \\
\hline Corynidae spp. & + & \\
\hline \multicolumn{3}{|l|}{ Ctenophora } \\
\hline \multicolumn{3}{|l|}{ Order Cydippida } \\
\hline \multicolumn{3}{|l|}{ Family Pleurobrachiidae } \\
\hline Hormiphora spp. & + & \\
\hline
\end{tabular}

\subsection{Jellyfish diversity: comparison of different sampling gears}

Thirty-seven species/genera of jellyfish were identified in the MOCNESS samples (Table 6), while 32 taxa were counted from samples collected with the macroplankton and Harstad trawls (Table 7).

The comparison of the data collected with different sampling methodologies during the G.O. Sars transatlantic cruise showed that only a few dominant species (e.g. Aglantha digitale, Nanomia cara, Beroe cucumis) were consistently sampled by all the gears. Relatively large species (e.g. Atolla spp., Pelagia noctiluca, Praya spp., Vogtia spp.) were mostly 
Table 6. G.O. Sars MOCNESS data set. List of jellyfish taxa collected in the 0-1000 m layer, in different North Atlantic regions. Data from Licandro et al. (2014).

\begin{tabular}{lccc}
\hline $\begin{array}{l}\text { North Atlantic region } \\
\text { Stations } \\
\text { Cruise }\end{array}$ & $\begin{array}{c}\text { Labrador Sea } \\
171\end{array}$ & $\begin{array}{c}\text { Irminger Sea } \\
166-170 \\
\text { G.O. Sars cruise }\end{array}$ & $\begin{array}{c}\text { Norwegian/Icelandic Sea } \\
152-165\end{array}$ \\
Latitude & \multicolumn{4}{c}{$60-63^{\circ} \mathrm{N}$} \\
Longitude & $59^{\circ} \mathrm{N}$ & $68^{\circ} \mathrm{N}$ \\
Time & $46^{\circ} \mathrm{W}$ & $36-24^{\circ} \mathrm{W}$ & $18^{\circ} \mathrm{W}-5^{\circ} \mathrm{E}$ \\
Date & Day & Day/night & Day/night \\
\cline { 2 - 4 } & 20 May 2013 & $14-17$ May 2013 & $3-12$ May 2013 \\
\hline
\end{tabular}

\section{Cnidaria \\ Hydrozoa}

Order Trachymedusae

Family Halicreatidae

Botrynema brucei

Halicreas minimum

Halicreatidae spp.

Family Rhopalonematidae

Aglantha digitale

Crossota rufobrunnea

Pantachogon haeckeli

Sminthea arctica

Rhopalonematidae spp.

Order Narcomedusae

Family Aeginidae

Aeginura grimaldii

Family Cuninidae

Solmissus incisa

Order Leptothecata

Family Mitrocomidae

Halopsis ocellata

Mitrocomella polydiademata

Family Tiarannidae

Chromatonema rubrum

Family Campanulariidae

Clytia islandica

Obelia spp.

Order Siphonophorae

Suborder Physonectae

Family Agalmatidae

Marrus orthocanna

Nanomia cara

Suborder Calycophorae

Family Hippopodiidae

Vogtia serrata

Family Diphyidae

Dimophyes arctica

Gilia reticulata

Lensia achilles

Lensia conoidea

Lensia hunter

Muggiaea bargmannea

Family Clausophyidae

Chuniphyes multidentata

Crystallophyes amygdalina

Heteropyramis crystallina

Family Sphaeronectidae

Sphaeronectes spp.

Order Anthoathecata

Family Hydractiniidae

Hydractinia areolata

$++$

$+$

Family Tubulariidae

Hybocodon spp.

$++$

$+$

$\begin{array}{ll}+ & + \\ + & +\end{array}$

$++$

$+\quad+$

$+\quad+$

$+$

$+$

$+$

$+$

$+$

$+$

$+$

$+$

$+$

$+$

$+$

+
+

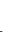

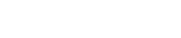

$+$

$+$

$+$

$+$

$+$

$\begin{array}{ll}+ & + \\ + & \\ + & +\end{array}$

$+$

$+$

$+$

$+$

$+$

$+$ 
Table 6. Continued.

\begin{tabular}{lccc}
\hline $\begin{array}{l}\text { North Atlantic region } \\
\text { Stations }\end{array}$ & $\begin{array}{c}\text { Labrador Sea } \\
\text { Cruise }\end{array}$ & $\begin{array}{c}\text { Irminger Sea } \\
166-170 \\
\text { G.O. Sars } \text { cruise }\end{array}$ & $\begin{array}{c}\text { Norwegian/Icelandic Sea } \\
152-165\end{array}$ \\
Latitude & \multicolumn{3}{c}{$62-68^{\circ} \mathrm{N}$} \\
Longitude & $59^{\circ} \mathrm{N}$ & $60-63^{\circ} \mathrm{N}$ & $18^{\circ} \mathrm{W}-5^{\circ} \mathrm{E}$ \\
Time & $46^{\circ} \mathrm{W}$ & $36-24^{\circ} \mathrm{W}$ & Day/night \\
Date & Day & Day/night & $3-12$ May 2013 \\
\hline
\end{tabular}

\begin{tabular}{|c|c|c|c|}
\hline \multicolumn{4}{|l|}{ Scyphozoa } \\
\hline \multicolumn{4}{|l|}{ Family Atollidae } \\
\hline Atolla parva & & & + \\
\hline Atolla wyvillei & + & + & \\
\hline \multicolumn{4}{|l|}{ Family Periphyllidae } \\
\hline Periphylla periphylla & + & + & \\
\hline \multicolumn{4}{|l|}{ CTENOPHORA } \\
\hline \multicolumn{4}{|l|}{ Order Cydippida } \\
\hline Unidentified Cydippid & + & + & + \\
\hline \multicolumn{4}{|l|}{ Family Mertensiidae } \\
\hline Mertensia ovиm & & & + \\
\hline Mertensiidae spp. & & & + \\
\hline \multicolumn{4}{|l|}{ Family Euplokamidae } \\
\hline Euplokamis spp. & & & + \\
\hline \multicolumn{4}{|l|}{ Order Lobata } \\
\hline \multicolumn{4}{|l|}{ Family Bolinopsidae } \\
\hline Bolinopsis infundibulum & & + & + \\
\hline \multicolumn{4}{|l|}{ Order Beroida } \\
\hline \multicolumn{4}{|l|}{ Family Beroidae } \\
\hline Beroe abyssicola & & & + \\
\hline Beroe cucumis & & + & + \\
\hline
\end{tabular}

St. 171

St. 170

St. 169

St. 168
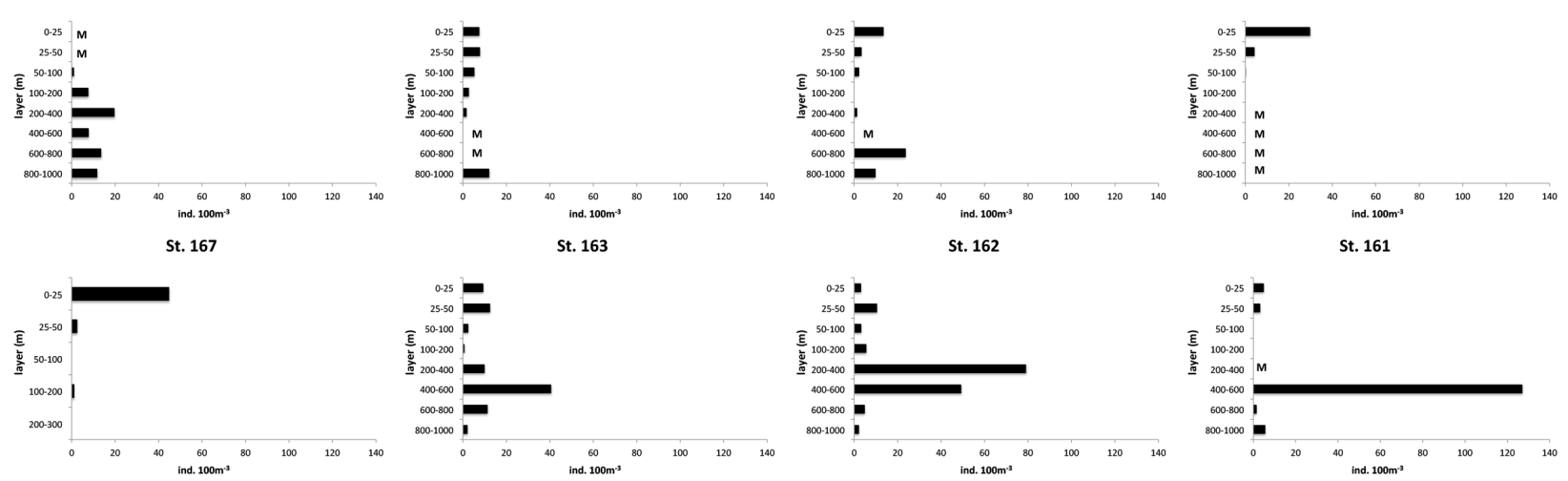

St. 160

St. 157

St. 154

St. 152
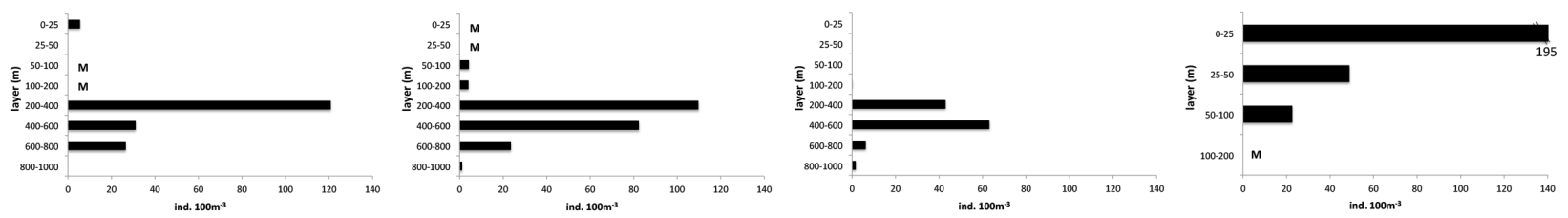

Figure 4. MOCNESS data set. Abundance of jellyfish at different depths in the $0-1000 \mathrm{~m}$ layer. Please note the shallower depths in stations 152 and 167. Station 155 is not shown. M: samples preserved in formalin, not yet analysed. 

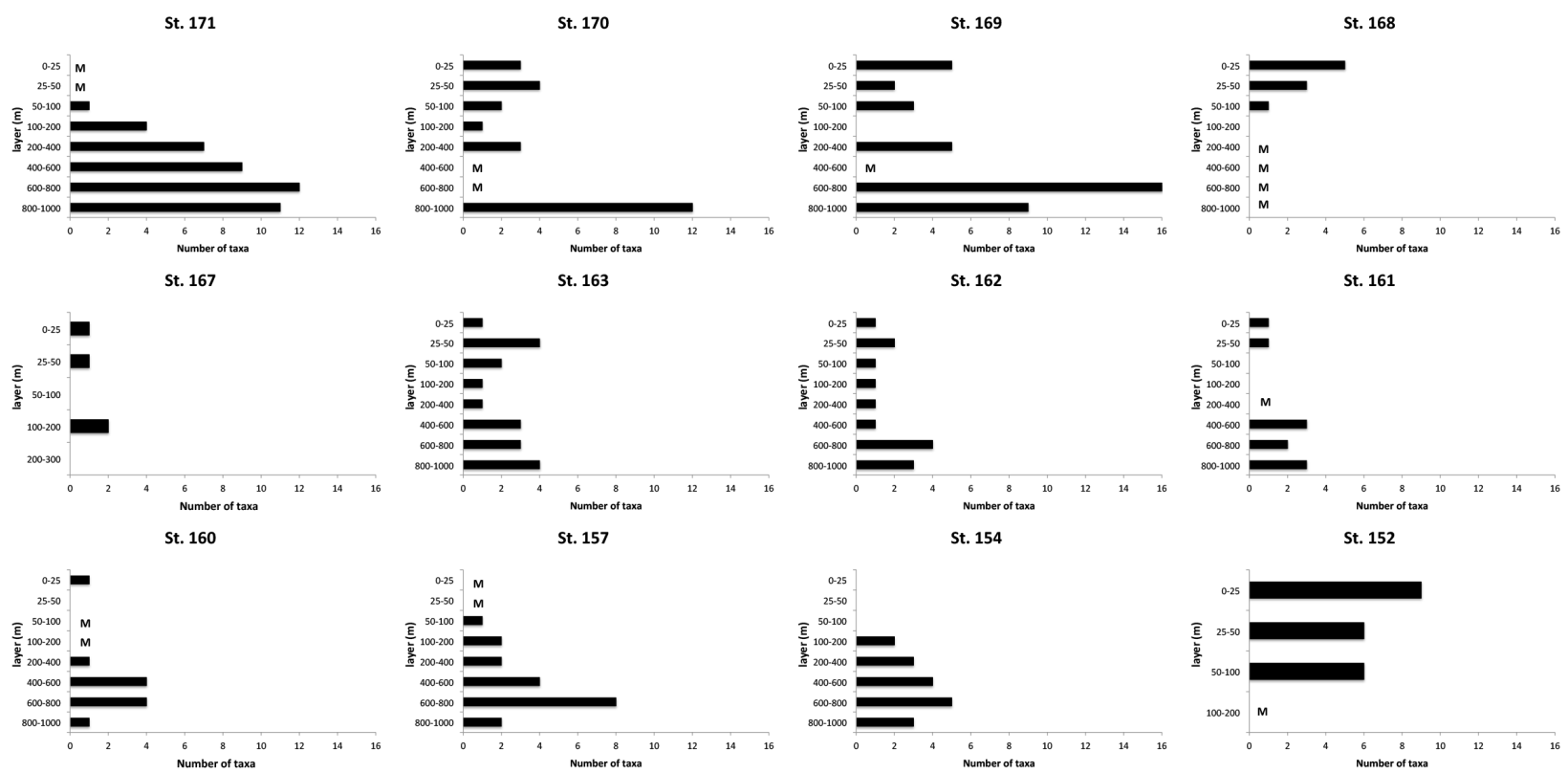

Figure 5. MOCNESS data set. Number of jellyfish taxa found at different depths in the $0-1000 \mathrm{~m}$ layer. Please note the shallower depths in stations 152 and 167. Station 155 is not shown. M: samples preserved in formalin, not yet analysed.

collected by big trawls (Table 7), while small hydrozoans (e.g. Clytia spp., Gilia spp., Muggiaea spp.) and early stages of Ctenophora were only caught by the smaller nets, such as the jellynet and the MOCNESS (Tables 4 and 6).

\subsection{Jellyfish blooms as identified by the CPR}

Based on CPR deployments from 2009 to 2012, jellyfish blooms occurred in all seasons, inshore and offshore, across the whole North Atlantic Basin (Fig. 6). Genetic analysis of jellyfish material collected from CPR samples identified blooms of small hydrozoans as well as relatively big scyphomedusae (Table 8). Among the first group, different species of colonial siphonophores were swarming inshore and offshore from summer to early autumn (Fig. 7). In the second group, blooms of the holopelagic cnidarian Pelagia noctiluca were recorded inshore and offshore from spring to late autumn, while swarms of the meropelagic Cyanea sp. were recorded in summer on the eastern and western Atlantic shelf.

\section{Discussion}

Sampling jellyfish is challenging as these organisms are delicate and their populations are often highly dispersed or unevenly distributed (Purcell, 2009). Conventional nets, which are usually made with monofilament woven nylon, often irremediably damage many delicate species of Cnidaria and Ctenophora, while softer materials such as silk or knitted polyester have been shown to better preserve the delicate bodies of gelatinous zooplankton (Braconnot, 1971; Raskoff

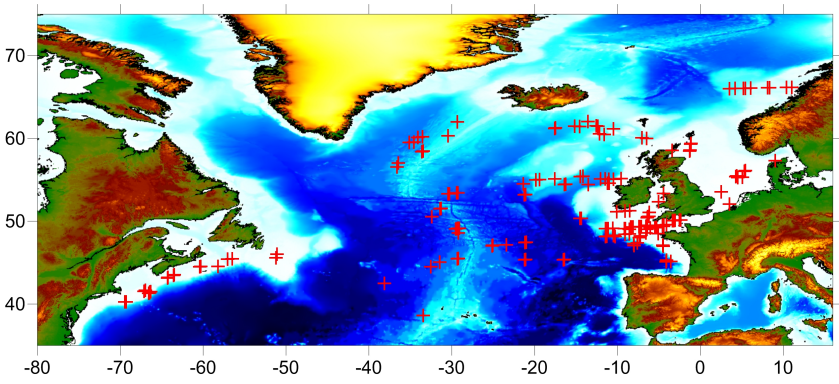

Figure 6. Jellyfish swarms recorded by the Continuous Plankton Recorder in 2009-2012.

et al., 2003). The relatively small mouth opening characterising standard plankton nets (e.g. circa $50 \mathrm{~cm}$ mouth diameter in bongo and WP2 nets) limits the volume of seawater filtered and therefore is not appropriate to provide quantitative records of jellyfish. Even though $200 \mu \mathrm{m}$ mesh size might be considered the most suitable to collect small hydromedusae (e.g. Cornelius, 1995), comparisons of samples collected with 300 and $700 \mu \mathrm{m}$ mesh demonstrated that the latter size represents the best compromise to quantitatively catch meso- and macroplanktonic gelatinous zooplankton, whilst limiting damage to their soft tissues (Braconnot, 1971; Buecher, 1997, 1999).

The data collected in epipelagic waters by the jellynet in the northern North Atlantic regions showed high variability in jellyfish standing stocks, with higher densities generally observed on the eastern and western North Atlantic shelves. Jellyfish diversity also varied, mainly in relation to different 
Table 7. G.O. Sars, Harstad and macroplankton data set. List of jellyfish taxa collected in the 0-1000 m layer, in different North Atlantic regions. Data from Licandro et al. (2014).

\begin{tabular}{lccc}
\hline North Atlantic region & Labrador Sea & Irminger Sea & Norwegian/Icelandic Sea \\
Stations & $125-127$ & $115-124$ & $101-111$ \\
Cruise & \multicolumn{4}{c}{ G. Sars cruise } \\
Latitude & $59^{\circ} \mathrm{N}$ & $60-63^{\circ} \mathrm{N}$ & $65-68^{\circ} \mathrm{N}$ \\
Longitude & $46^{\circ} \mathrm{W}$ & $36-25^{\circ} \mathrm{W}$ & $15-01^{\circ} \mathrm{W}$ \\
Time & Day & Day/night & Day/night \\
Date & 20 May 2013 & $15-17$ May 2013 & $5-11$ May 2013 \\
\hline
\end{tabular}

Cnidaria

\begin{tabular}{|c|c|c|c|}
\hline Hydrozoa & & & \\
\hline Order Trachymedusae & & & \\
\hline Family Halicreatidae & & & \\
\hline Halicreas minimum & + & + & \\
\hline Halitrephes maasi & + & + & \\
\hline Halicreatidae spp. & + & + & \\
\hline Family Rhopalonematidae & & & \\
\hline Aglantha digitale & + & + & + \\
\hline Colobonema sericeum & + & + & \\
\hline Crossota rufobrunnea & & + & \\
\hline Pantachogon haeckeli & + & + & \\
\hline Rhopalonematidae spp. & & + & \\
\hline Order Narcomedusae & & & \\
\hline Family Aeginidae & & & \\
\hline Aeginura grimaldii & + & + & \\
\hline Family Cuninidae & & & \\
\hline Solmissus incisa & + & + & \\
\hline Order Leptothecata & & & \\
\hline Family Laodiceidae & & & \\
\hline Ptychogena lactea & & & + \\
\hline Family Tiarannidae & & & \\
\hline Chromatonema rubrum & & + & \\
\hline Modeeria rotunda & + & + & \\
\hline Order Siphonophorae & & & \\
\hline Suborder Physonectae & & & \\
\hline Family Agalmatidae & & & \\
\hline Marrus orthocanna & & & + \\
\hline Nanomia cara & & + & \\
\hline Suborder Calycophorae & & & \\
\hline Family Prayinae & & & \\
\hline Praya dubia & + & + & \\
\hline Family Hippopodiidae & & & \\
\hline Vogtia glabra & + & + & \\
\hline Vogtia serrata & + & + & \\
\hline Family Diphyidae & & & \\
\hline Dimophyes arctica & + & & + \\
\hline Lensia conoidea & & + & \\
\hline Nectodamas diomedeae & & + & \\
\hline Family Clausophyidae & & & \\
\hline Chuniphyes multidentata & + & + & \\
\hline Order Anthoathecata & & & \\
\hline Family Bythotiaridae & & & \\
\hline Bythotiara murrayi & & + & \\
\hline
\end{tabular}


Table 7. Continued.

\begin{tabular}{|c|c|c|c|}
\hline North Atlantic region & Labrador Sea & Irminger Sea & Norwegian/Icelandic Sea \\
\hline Stations & $125-127$ & $115-124$ & $101-111$ \\
\hline Cruise & \multicolumn{3}{|c|}{ G.O. Sars cruise } \\
\hline Latitude & $59^{\circ} \mathrm{N}$ & $60-63^{\circ} \mathrm{N}$ & $65-68^{\circ} \mathrm{N}$ \\
\hline Longitude & $46^{\circ} \mathrm{W}$ & $36-25^{\circ} \mathrm{W}$ & $15-01^{\circ} \mathrm{W}$ \\
\hline Time & Day & Day/night & Day/night \\
\hline Date & 20 May 2013 & 15-17 May 2013 & 5-11 May 2013 \\
\hline \multicolumn{4}{|l|}{ Scyphozoa } \\
\hline \multicolumn{4}{|l|}{ Family Atollidae } \\
\hline Atolla chuni & & + & \\
\hline Atolla parva & & + & + \\
\hline Atolla vanhoeffeni & + & + & \\
\hline Atolla wyvillei & + & + & \\
\hline Atolla sp. & & + & + \\
\hline \multicolumn{4}{|l|}{ Family Periphyllidae } \\
\hline Periphylla periphylla & + & + & \\
\hline \multicolumn{4}{|l|}{ Family Pelagiidae } \\
\hline Pelagia noctiluca & & + & + \\
\hline \multicolumn{4}{|l|}{ Ctenophora } \\
\hline \multicolumn{4}{|l|}{ Order Cydippida } \\
\hline \multicolumn{4}{|l|}{ Family Mertensiidae } \\
\hline Mertensia ovum & & & + \\
\hline \multicolumn{4}{|l|}{ Order Beroida } \\
\hline \multicolumn{4}{|l|}{ Family Beroidae } \\
\hline Beroe abyssicola & & & + \\
\hline Beroe cucumis & & + & + \\
\hline Beroe gracilis & & + & \\
\hline Beroe spp. & & & + \\
\hline
\end{tabular}

water masses and bathymetry. The populations were less diverse in Arctic waters than on the northeastern Atlantic shelf, where more meropelagic medusae are present.

In agreement with previous studies (Hosia et al., 2008; Purcell, 2009, and references therein), a comparison of records collected with different nets during the G.O. Sars transatlantic cruise confirms that different sampling gears provide different information on jellyfish populations. Indeed, the big trawls (i.e. $\geq 6 \mathrm{~m}$ mouth opening and $3 \mathrm{~cm}$ mesh size in this study) mostly collected relatively large scyphozoan and hydrozoan species such as Atolla spp., Pelagia spp., Praya spp. and Vogtia spp., due to the large mesh size and large volume filtered. Small hydrozoans (e.g. Clytia spp., Gilia spp., Muggiaea spp.) and early stages of Ctenophora were only caught by the smaller nets (i.e. $1 \mathrm{~m}$ mouth opening and $\leq 800 \mu \mathrm{m}$ mesh size in this study). Therefore sampling gear should be carefully considered when programmes are set up to monitor different types of jellyfish communities.

Overall, the hydrozoans Aglantha digitale, Dimophyes arctica and Nanomia cara and the ctenophores belonging to the family Mertensiidae and Beroe spp. were the epipelagic species most frequently recorded in the northern North At- lantic region during spring-summer. The presence of these key taxa was detected by different sampling gears used during the G.O. Sars transatlantic cruise, even if estimates of their abundance varied.

The use of modern technology, in particular of remotely operated vehicles equipped with underwater cameras and video systems, has proven to be very valuable in the collection of information on gelatinous plankton in situ, particularly in deep waters (e.g. Lindsay et al., 2008; Stemmann et al., 2008). Nevertheless, video systems are still quite costly and are therefore unlikely to be employed for standard jellyfish monitoring. Ocean-surface and shore-based surveys have been used to provide semi-quantitative/qualitative estimates of relatively big scyphomedusae and other gelatinous plankton (Purcell, 2009, and references therein). Visual observations from a ship or from a pier are, however, biased towards species of large size and relatively simple taxonomic identification. Therefore these methodologies cannot provide reliable information on the abundance and composition of jellyfish populations throughout the oceans.

The CPR Survey is the monitoring programme that covers the greatest spatial (tens to thousands of kilometres) and tem- 
Table 8. Identity of cnidarian tissues collected from CPR samples and identified based upon mt16S rDNA analysis. Sampling information is also indicated. *Sample identified by visual inspection.

\begin{tabular}{|c|c|c|c|c|c|c|}
\hline CPR tows & Latitude & Longitude & Month & Year & Taxa identified & Class \\
\hline $330 \mathrm{M}$ & 58.05 & 1.90 & 8 & 2006 & Cyanea sp. & Scyphozoa \\
\hline $330 \mathrm{M}$ & 58.18 & 2.48 & 8 & 2006 & Cyanea sp. & Scyphozoa \\
\hline 535ZB & 49.83 & -41.66 & 3 & 2007 & Agalmatidae & Hydrozoa \\
\hline 438BB & 45.63 & -18.80 & 9 & 2007 & Pelagia noctiluca & Scyphozoa \\
\hline 438BC & 43.50 & -25.57 & 9 & 2007 & Halistemma rubrum & Hydrozoa \\
\hline 3030PR & 49.37 & -4.01 & 10 & 2007 & Muggiaea atlantica & Hydrozoa \\
\hline 460W & 54.48 & -16.59 & 10 & 2007 & Pelagia noctiluca & Scyphozoa \\
\hline $460 \mathrm{~W}$ & 54.48 & -16.59 & 10 & 2007 & Diphyes dispar & Hydrozoa \\
\hline $460 \mathrm{~W}$ & 54.48 & -16.59 & 10 & 2007 & Pelagia noctiluca & Scyphozoa \\
\hline 707A & 58.29 & -1.59 & 11 & 2007 & Apolemia uvaria & Hydrozoa \\
\hline $708 \mathrm{~A}$ & 58.31 & -1.60 & 12 & 2007 & Pelagia noctiluca & Scyphozoa \\
\hline $464 W$ & 54.72 & -18.12 & 7 & 2008 & Pelagia noctiluca & Scyphozoa \\
\hline $464 \mathrm{~W}$ & 54.90 & -15.55 & 7 & 2008 & Pelagia noctiluca & Scyphozoa \\
\hline $464 \mathrm{~W}$ & 54.70 & -18.41 & 7 & 2008 & Pelagia noctiluca & Scyphozoa \\
\hline 80FA & 54.14 & -25.45 & 8 & 2008 & Pelagia noctiluca & Scyphozoa \\
\hline 80FA & 54.16 & -25.18 & 8 & 2008 & Pelagia noctiluca & Scyphozoa \\
\hline 571SA & 45.45 & -4.03 & 11 & 2008 & Pelagia noctiluca & Scyphozoa \\
\hline 571SA & 45.60 & -4.10 & 11 & 2008 & Pelagia noctiluca & Scyphozoa \\
\hline $83 \mathrm{FA}$ & 54.47 & -21.47 & 12 & 2008 & Pelagia noctiluca & Scyphozoa \\
\hline $465 \mathrm{BC}$ & 47.10 & -25.04 & 12 & 2009 & Pelagia noctiluca & Scyphozoa \\
\hline $748 \mathrm{~V}$ & 60.01 & -6.48 & 12 & 2009 & Pelagia noctiluca & Scyphozoa \\
\hline $468 \mathrm{BC}$ & 45.46 & -29.34 & 3 & 2010 & Pelagia noctiluca & Scyphozoa \\
\hline $349 \mathrm{EA}$ & 45.59 & -51.22 & 7 & 2010 & Cyanea sp. & Scyphozoa \\
\hline $349 \mathrm{EA}$ & 46.00 & -51.07 & 7 & 2010 & Cyanea sp. & Scyphozoa \\
\hline $342 \mathrm{PR}$ & 48.50 & -5.08 & 11 & 2010 & Pelagia noctiluca & Scyphozoa \\
\hline 488BA & 49.12 & -9.03 & 10 & 2011 & Aglantha digitale* & Hydrozoa \\
\hline 373EB & 42.03 & -66.28 & 1 & 2012 & Agalma elegans & Hydrozoa \\
\hline 499BD & 42.51 & -38.14 & 8 & 2012 & Halistemma sp. & Hydrozoa \\
\hline $364 \mathrm{PR}$ & 49.57 & -4.08 & 10 & 2012 & Apolemia spp. & Hydrozoa \\
\hline
\end{tabular}

poral (monthly to multidecadal) scales, sampling plankton at the surface across the whole North Atlantic in regions where information on plankton is typically not available (Richardson et al., 2006). It therefore offers a unique opportunity to document jellyfish swarms, which are events usually occurring over distances of tens to hundreds of kilometres (e.g. Brodeur et al., 2008) and for which large-scale methods of data collection are needed (Purcell, 2009). In contrast with what was previously hypothesised (Atrill et al., 2007; Gibbons and Richardson, 2009), the CPR is able to detect blooms of meroplanktonic as well as of holoplanktonic hydrozoans and scyphozoans. Outbreaks of the scyphomedusa Pelagia noctiluca, recorded by the CPR off Ireland in October 2007, were confirmed by net tows (Fig. 2 in Licandro et al., 2010, comparing CPR swarms events and records from Doyle et al., 2008), suggesting that the CPR can provide reliable information to help clarify the regions and periods in which jellyfish prefer to bloom.

Indeed, the reanalysis of CPR samples collected in recent years showed that jellyfish blooms can occur in coastal and offshore waters the whole year round. Genetic analysis of
CPR cnidarian material indicates that meroplanktonic jellyfish (e.g. the scyphomedusa Cyanea sp.), which are characterised by the alternation of a benthic polyp stage and a pelagic medusa, tend to bloom over the shelf, while holoplanktonic species (e.g. P. noctiluca and different species of hydrozoan siphonophores) bloom both inshore and offshore. Based on the CPR, P. noctiluca and other hydrozoan siphonophores including Muggiaea atlantica, Halistemma spp. and other agalmatidae are among the main swarming species in the central and southern North Atlantic regions. Those observations, in particular the high abundance of small hydrozoan siphonophores in coastal regions, while they are yet to be confirmed, are in agreement with the information collected in the Bay of Biscay and Gulf of Cádiz.

Overall, records of jellyfish swarms reported by the CPR can help to identify North Atlantic regions more impacted by blooming events and help to discern whether environmental change and/or anthropogenic pressure can explain increasing jellyfish occurrence.

The new information on jellyfish abundance, diversity and distribution across the North Atlantic provided here presents 
Table 9. DNA sequences (mt16S rDNA) identified from cnidarian taxa collected during project EURO-BASIN in different North Atlantic regions.

\begin{tabular}{|c|c|c|}
\hline Taxa identified & Region & GenBank accession number \\
\hline & & $16 \mathrm{~S}$ \\
\hline \multicolumn{3}{|l|}{ HYDROZOA } \\
\hline \multicolumn{3}{|l|}{ Order Trachymedusae } \\
\hline \multicolumn{3}{|l|}{ Family Halicreatidae } \\
\hline \multicolumn{3}{|l|}{ Family Rhopalonematidae } \\
\hline Crossota rufobrunnea & NW Atlantic & KJ866190 \\
\hline Pantachogon haeckelii & NW Atlantic & KJ866191 \\
\hline Pantachogon spp. & NW Atlantic & KJ866192 \\
\hline Sminthea arctica & NE Atlantic & KJ866185 \\
\hline \multicolumn{3}{|l|}{ Order Narcomedusae } \\
\hline \multicolumn{3}{|l|}{ Family Aeginidae } \\
\hline \multicolumn{3}{|l|}{ Family Cuninidae } \\
\hline Solmissus spp. & NE Atlantic & KJ866198 \\
\hline \multicolumn{3}{|l|}{ Order Leptothecata } \\
\hline \multicolumn{3}{|l|}{ Suborder Conica } \\
\hline \multicolumn{3}{|l|}{ Family Laodiceidae } \\
\hline Ptychogena lactea & NE Atlantic & KJ866187 \\
\hline \multicolumn{3}{|l|}{ Family Mitrocomidae } \\
\hline Mitrocomella polydiademata & NE Atlantic & KJ866197 \\
\hline \multicolumn{3}{|l|}{ Suborder Proboscoida } \\
\hline \multicolumn{3}{|l|}{ Family Campanulariidae } \\
\hline Clytia islandica & North Atlantic & KJ866184 \\
\hline \multicolumn{3}{|l|}{ Order Siphonophorae } \\
\hline \multicolumn{3}{|l|}{ Suborder Physonectae } \\
\hline \multicolumn{3}{|l|}{ Family Agalmatidae } \\
\hline Halistemma rubrum & NE Atlantic & KJ866203 \\
\hline Marrus orthocanna & NE Atlantic & KJ866186 \\
\hline Nanomia cara & NE Atlantic & KJ866204 \\
\hline Nanomia cara & NE Atlantic & KJ866206 \\
\hline \multicolumn{3}{|l|}{ Suborder Calycophorae } \\
\hline \multicolumn{3}{|l|}{ Family Hippopodiidae } \\
\hline Vogtia glabra & North Atlantic & KJ866183 \\
\hline \multicolumn{3}{|l|}{ Family Diphyidae } \\
\hline Dimophyes arctica & NE Atlantic & KJ866200 \\
\hline Gilia reticulata & NW Atlantic & KJ866188 \\
\hline Lensia achilles & NE Atlantic & KJ866193 \\
\hline Lensia conoidea & NE Atlantic & KJ866201 \\
\hline Lensia sp. & NE Atlantic & KJ866205 \\
\hline Muggiaea bargmannea & NE Atlantic & KJ866199 \\
\hline \multicolumn{3}{|l|}{ Family Clausophyidae } \\
\hline Chuniphyes multidentata & NE Atlantic & KJ866202 \\
\hline Heteropyramis crystallina & NE Atlantic & KJ866194 \\
\hline Heteropyramis sp. & NE Atlantic & KJ866196 \\
\hline
\end{tabular}

an improved baseline for future analysis of jellyfish dynamics. Our use of multiple methods and confirmation that CPR, for example, is a suitable source of data shows that the potential for analysing jellyfish populations is high. We also highlighted differences between sampling gears and the target taxa they are best suited for, and encourage a careful de- sign of future monitoring of jellyfish. We expect that the increased negative commercial impact by jellyfish in the North Atlantic (e.g. salmon farms, tourism references) will give rise to more attention and funding to understand the dynamics of these taxa. 

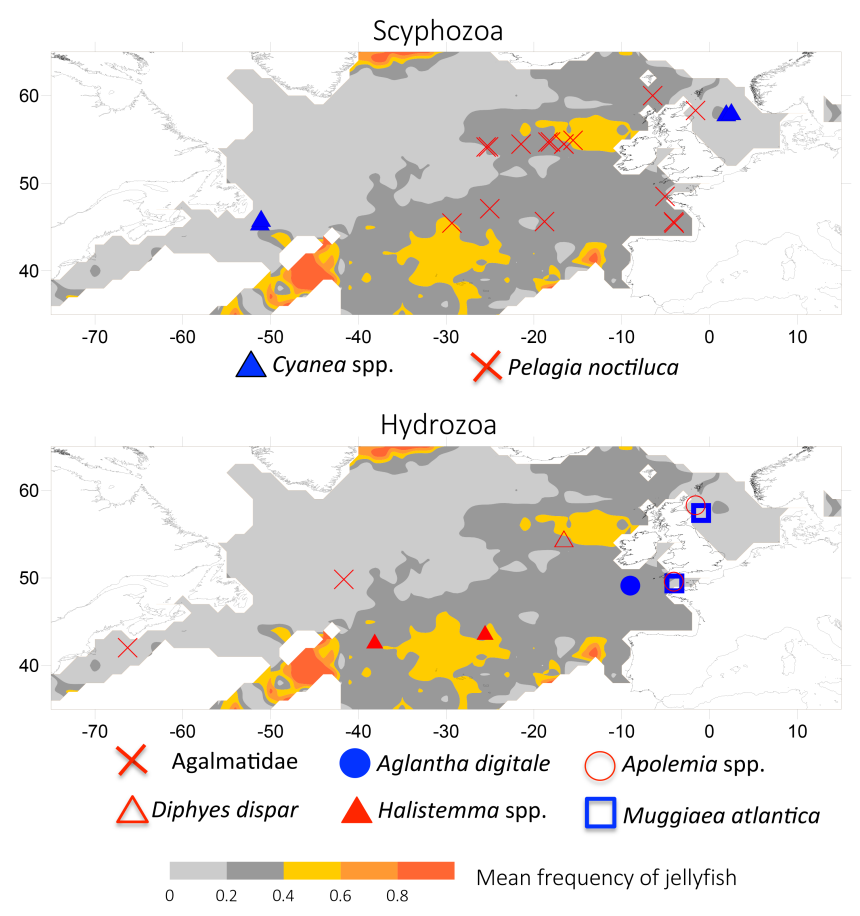

Figure 7. Jellyfish blooming species identified by genetic analysis from jellyfish material collected in CPR samples. The mean frequency of jellyfish presence recorded in 2000-2009 is also shown.

Acknowledgements. We wish to acknowledge the Instituto Español de Oceanografía (IEO) from Cádiz and AZTI Technalia from San Sebastián (Spain) for the collection of plankton samples in the Gulf of Cádiz and in the Bay of Biscay. Thanks are particularly due to Marcos Llope and Carmen González from IEO and to Unai Cotano from AZTI. Thanks also to Laura Prieto from CSIC and César Vilas from IEO in Cádiz, Spain, for providing jellyfish specimens preserved in ethanol for DNA barcoding. We are particularly grateful to the heads of mission and scientists on board the EURO-BASIN cruises, for facilitating in any possible manner the collection and identification of jellyfish specimens. This work was supported by project EURO-BASIN (ref. 264933, 7FP, European Union).

Edited by: G. Melvin

\section{References}

Attrill, M., Wright, J., and Edwards, M.: Climate-related increases in jellyfish frequency suggest a more gelatinous future for the North Sea, Limnol. Oceanogr., 52, 480-485, 2007.

Bouillon, J., Gravili, C., Pagès, F., Gili, J. M., and Boero, F.: An introduction to Hydrozoa, Mémoires du Muséum national d'Histoire naturelle no., Publications Scientifiques du Muséum, Paris, 2006.

Braconnot, J. C.: Contribution à l'étude biologique et écologique des Tuniciers pélagiques Salpides et Doliolides I. Hydrologie et écologie des Salpides, Vie et Milieu, 22, 257-286, 1971.
Brodeur, R. D., Mills C. E., Overland J. E., Walters, G. E., and Schumacher, J. D.: Evidence for a substantial increase in gelatinous zooplankton in the Bering Sea, with possible links to climate change, Fish. Oceanogr., 8, 296-306, 1999.

Brodeur, R. D., Decker, M. B., Ciannelli, L., Purcell, J. E., Bond, N. A., Stabeno, P. J., Acuna, E., and Hunt Jr., G. L.: The rise and fall of jellyfish in the Bering Sea in relation to climate regime shifts, Progr. Oceanogr., 77, 103-111, 2008.

Brotz, L., Cheung, W. W. L., Kleisner, K., Pakhomov, E., and Pauly, D.: Increasing jellyfish populations: trends in large marine ecosystems, Hydrobiologia, 690, 3-20, 2012.

Buecher, E.: Distribution and abundance of Pleurobrachia rhodopis (Cydippid Ctenophore) in the Bay of Villefranche-sur-Mer (Northwestern Mediterranean) from three different planktonic time series, Ann. Inst. Oceanogr. Paris, 72, 173-184, 1997.

Buecher, E.: Appearance of Chelophyes appendiculata and Abylopsis tetragona (Cnidaria, Siphonophora) in the Bay of Villefranche, northwestern Mediterranean, J. Sea Res., 41, 295-307, 1999.

Carré, C. and Carré, D.: Les siphonophores, in: Grassé P. P. Traité de Zoologie: Anatomie, Systématique, Biologie, Masson, Paris, 1993.

Collins, A. G., Bentlage, B., Lindner, A., Lindsay, D., Haddock, S. H. D., Jarms, G., Norenburg, J. L., Jankowski, T., and Cartwright, P.: Phylogenetics of Trachylina (Cnidaria: Hydrozoa) with new insights on the evolution of some problematical taxa, J. Mar. Biol. Ass. UK, 88, 1673-1685, 2008.

Condon, R. H., Duarte, C. M., Pitt, K. A., Robinson, K. L., Lucas, C. H., Shuterland, K. R., Mianzan, H. W., Bogeberg, M., Purcell, J. E., Decker, M. B., Uye, S., Madin, L. P., Brodeur, R. D., Haddock, S. H. D., Malej, A., Parry, G. D., Eriksen, E., Quiñones, J., Acha, M., Harvey, M., Arthur, J. M., and Graham, W. M.: Recurrent jellyfish blooms are a consequence of global oscillations, Proc. Natl. Acad. Sci. USA, 110, 1000-1005, 2013.

Condon, R. H., Graham, W. M., Duarte, C. M., Pitt, K. A., Lucas, C. H., Haddock, S. H. D., Shuterland, K. R., Robinson, K. L., Dawson, M. N., Decker, M. B., Mills, C. E., Purcell, J. E., Malej, A., Mianzan, H. W., Uye, S., Gelcich, S., and Madin, L. P.: Questioning the rise of gelatinous zooplankton in the world's oceans, Bioscience, 62, 160-169, 2012.

Cornelius, P. F. S.: North-west European thecate hydroids and their medusae. Part 1. Introduction, Laodiceidae to Haleciidae, Shrewsbury: Field Studies Council, Synopses of the British Fauna no. 50, 1995.

Cunningham, C. W. and Buss, L. W.: Molecular evidence for multiple episodes of paedomorphosis in the family Hydractiniidae, Biochem.1 Syst. Ecol., 21, 57-69, 1993.

Doyle, T. K., De Haas, H., Cotton, D., Dorschel, B., Cummins, V., Houghton, J. D. R., Davenport, J., and Hays, G. C.: Widespread occurrence of the jellyfish Pelagia noctiluca in Irish coastal and shelf waters, J. Plankton Res., 30, 963-968, 2008.

Gibbons, M. J., and Richardson, A. J.: Patterns of jellyfish abundance in the North Atlantic, Hydrobiologia, 616, 51-65, 2009.

Haddock, S. H. D., Dunn, C. W., and Pugh, P. R.: A re-examination of siphonophore terminology and morphology, applied to the description of two new prayine species with remarkable bio-optical properties, J. Mar. Biol. Ass. UK, 85, 695-707, 2005. 
Hall, T.: BioEdit: a user-friendly biological sequence alignment editor and analysis program for Windows 95/98/NT, Nucl. Acids. Symp. Ser, 41, 95-98, 1999.

Hosia, A., Stemmann, L., and Youngbluth, M.: Distribution of netcollected planktonic cnidarians along the northern Mid-Atlantic Ridge and their associations with the main water masses, DeepSea Res. Pt. II, 55, 106-118, 2008.

Katoh, K., Kuma, K., Toh, H., MiyataKatoh, T., and Kumah, K.: MAFFT version 5: improvement in accuracy of multiple sequence alignment, Nucleic Acids Res., 33, 511-518, 1995.

Kawahara, M., Uye, S., Ohtsu, K., and Iizumi, H.: Unusual population explosion of the giant jellyfish Nemopilema nomurai (Scyphozoa: Rhizostomeae) in East Asian waters, Mar. Ecol. Progr. Ser., 307, 161-173, 2006.

Kirby, R. R., Johns, D. G., and Lindley, J. A.: Fathers in hot water: rising sea temperatures and a northeastern Atlantic pipefish baby boom, Biol. Lett. 2, 597-600, doi:10.1098/rsbl.2006.0530, 2006.

Kirkpatrick, P. A. and Pugh, P. R.: Siphonophores and Velellids, Synopses of the British Fauna (New Series) no. 29, Backhuys, London, 1984.

Kramp, P. L.: The Hydromedusae of the Atlantic Ocean and adjacent waters, Dana-Report no. 46, The Carlsberg Foundation, 1959.

Licandro, P.: Abundance of Cnidaria and Ctenophora in the Gulf of Cadiz (2010), doi:10.1594/PANGAEA.830265, 2014a.

Licandro, P.: Abundance of Cnidaria and Ctenophora in the Bay of Biscay (May 2010), doi:10.1594/PANGAEA.830263, 2014b.

Licandro, P. and Blackett, M.: Abundance of Cnidaria and Ctenophora in the North Atlantic sampled during the M87/1 cruise in April 2012, doi:10.1594/PANGAEA.829714, 2014.

Licandro, P. and Carré, C.: Meduse, Sifonofori, Ctenofori, in: Guida al riconoscimento del plancton nei mari italiani, Vol. II - Zooplancton neritico, Ministero dell' Ambiente e della Tutela del Territorio e del Mare - ICRAM, edited by: Avancini, M. C. A. M., Di Girolamo, I., Innamorati, E., Magaletti, E., and Sertorio Zunini, T., 11-44, tavv. 1-23, Roma, 2006.

Licandro, P. and Hosia, A.: Abundance of Cnidaria and Ctenophora in the North Atlantic sampled during the G.O. Sars Cruise in May 2013, doi:10.1594/PANGAEA.828646, 2014.

Licandro, P. and Kennedy, J.: Abundance of Cnidaria and Ctenophora in the North Western Atlantic collected in August and September 2011, doi:10.1594/PANGAEA.828647, 2014.

Licandro, P. and Raab, K.: Abundance of Cnidaria and Ctenophora in the Icelandic Sea sampled in May 2012, doi:10.1594/PANGAEA.828648, 2014.

Licandro, P., Conway, D. V. P., Daly Yahia, M. N., Fernandez de Puelles, M. L., Gasparini, S., Hecq, J. H., Tranter, P., and Kirby, R. R.: A blooming jellyfish in the northeast Atlantic and Mediterranean, Biology Lett., 6, 688-691, doi:10.1098/rsbl.2010.0150, 2010.

Licandro, P., Blackett, M., Hosia, A., Kennedy, J., and Raab, K.: Presence and absence of Cnidaria and Ctenophora taxa in the North Atlantic, doi:10.1594/PANGAEA.830244, 2014

Lindsay, D., Pages, F., Corbera, J., Miyake, H., Hunt, J. C., Ichikawa, T., Segawa, K., and Yoshida, H.: The anthomedusan fauna of the Japan Trench: preliminary results from in situ surveys with manned and unmanned vehicles, J. Mar. Biol. Ass. UK, 88, 1519-1539, 2008.
Mapstone, G.: Siphonophora (Cnidaria: Hydrozoa) of Canadian Pacific waters, NRC Research Press, Ottawa, 2009.

Mianzan, H. W. and Cornelius, P. F. S.: Cubomedusae and Scyphomedusae. In: Boltovskoy D. South Atlantic Zooplankton, Backhuys, Leiden, 513-559, 1999.

Mills, C.: Jellyfish blooms: are populations increasing globally in response to changing ocean conditions?, Hydrobiologia, 451, 55-68, 2001.

Mills, C. and Haddock, S. H. D.: Ctenophora, in: The Light and Smith Manual: Intertidal Invertebrates from Central California to Oregon, edited by: Carlton, J. T., University of California Press, Berkeley and Los Angeles, 189-199, 2007.

Nedreaas, K. and Smedstad, O. M.: Abundance and distribution of postlarvae in the 0-group saithe survey in the North Sea and the Northeast Arctic in 1986 and 1987, ICES CM 1987/G:31, 1987.

Pugh, P. R.: Siphonophorae, in: South Atlantic Zooplankton, edited by: Boltovskoy, D., Backhuys, Leiden, 467-511, 1999.

Purcell, J. E.: Extension of methods for jellyfish and ctenophore trophic ecology to large-scale research, Hydrobiologia, 616, 23 50, 2009.

Raskoff, K. A., Sommer, F. A., Hamner, W. M., and Cross, K. M.: Collection and culture techniques for gelatinous zooplankton, Biol. Bull., 204, 68-80, 2003.

Richardson, A. J., Walne, A. W., John, A. W. G., Jonas, T. D., Lindley, J. A., Sims, D. W., Stevens, D., and Witt, M. Using continuous plankton recorder data, Progr. Oceanogr., 68, 27-74, 2006.

Ripley, S. J., Baker, A. C., Miller, P. I., Walne, A. W., and Schroeder, D. C.: Development and validation of a molecular technique for the analysis of archived formalin-preserved phytoplankton samples permits retrospective assessment of Emiliania huxleyi communities, J. Microbiol. Methods, 73, 118-124, 2008.

Russel, F. S.: The medusae of the British Isles., no. 1, Cambridge University Press, Cambridge, 1953.

Schroth, W., Jarms, G., Streit, B., and Schierwater, B.: Speciation and phylogeography in the cosmopolitan marine moon jelly, $\mathrm{Au}$ relia sp, BMC Evolutionary Biology, 2, 1-10, 2002.

Schuchert, P.: North-West European Athecate Hydroids and their Medusae, Synopses of the British Fauna (New Series) no. 59, Field Studies Council, London, 2012.

Stemmann, L., Hosia, A., Youngbluth, M. J., Søiland, H., Picheral, M., and Gorsky, G.: Vertical distribution (0-1000 m) of macrozooplankton, estimated using the Underwater Video Profiler, in different hydrographic regimes along the northern portion of the Mid-Atlantic Ridge, Deep-Sea Res. Pt. II, 55, 94-105, 2008.

Wiebe, P. H. and Benfield, M. C.: From the Hensen net toward fourdimensional biological oceanography, Prog. Oceanogr., 56, 7136, 2003.

Wrobel, D. and Mills, C.: Pacific Coast Pelagic Invertebrates: A Guide to the Common Gelatinous Animals, Sea Challengers and Monterey Bay Aquarium, 1998.

Xian, W., Kang, B., and Liu, R.: Jellyfish blooms in the Yangtze Estuary, Science, 307, p. 41, 2005. 